\title{
Abstracts for the 36th Human Genetics Society of Australasia Annual Scientific Meeting Canberra, Australia, July $22-25,2012$
}

1. HMG COA SYNTHASE DEFICIENCY- HOW COMMON IS IT AND HOW GOOD ARE OUR MARKERS?

\author{
K. Carpenter $^{1,2}{ }^{\text {, F. Moore' }}{ }^{\text {, K. Bhattacharya }}{ }^{2,3}$ \\ ${ }^{1}$ NSW Biochemical Genetics Service, The Children's Hospital at Westmead, Australia \\ ${ }^{2}$ Disciplines of Paediatrics \& Child Health and Genetic Medicine, University of \\ Sydney, Australia \\ ${ }^{3}$ Genetic Metabolic Diseases Service, The Children's Hospital at Westmead, Australia
}

Mitochondrial 3-hydroxy-3-methylglutaryl-CoA synthase (HMGCS2) is involved in ketone body production. Patients with a severe deficiency typically present with hypoglycaemia and a hypoketotic dicarboxylic aciduria during inter-current illness. The description by Pitt et al ${ }^{1}$ of characteristic key marker metabolites detected on organic acid analysis has raised our awareness of this condition and these markers are now routinely sought in all patients referred for testing.

Since the identification of our first patient in 2009 we have identified a further 5 patients, (4 prospectively, 1 following re-evaluation of previous organic acid analysis), with a relatively hypoketotic dicarboxylic aciduria and the presence of several of the markers previously described. All presented between 6 months and 2 years of age following a period of reduced intake. One of these patients has been confirmed as a heterozygote for a mutation in HMGCS2. Mutation analysis in the remaining patients is in progress.

We have looked at excretion of marker compounds in normal and ketotic individuals and compared the results with levels seen in confirmed and suspected patients. 4-hydroxy-6-methyl-2pyrone (4HMP) appears to remain a strong positive marker as does 3-hydroxybutyrylglycine.

The significance of other marker compounds thought to be derived from hexanoyl CoA, trans-hex-2-enoyl CoA and 3hydroxyhexanoyl CoA remains unclear but may point to combinations of heterozygous mutations in genes involved in ketone body synthesis which predispose to acute presentation during inter-current illness.

\section{COMPLEX IV DEFICIENCY IN A GIRL WITH 22q11.2} DELETION AND ADJACENT SEGMENTAL UNIPARENTAL DISOMY

A. McWhinney', H. Heussler' ${ }^{2}$, B. McDermott ${ }^{2}$, M. Doody', G. Price' , J. McGill', F. Bowling ${ }^{2}$

${ }^{1}$ Mater Pathology, South Brisbane, Queensland,

${ }^{2}$ Mater Children's Hospital, South Brisbane, Queensland
A 9 year old girl presented at 1 year of age with microcephaly, global developmental delay, hypotonia, severe feeding difficulties and bilateral combined hearing loss. Behavioural problems developed with hyperactivity, inattention and some autistic features. There was a maternal family history of intellectual impairment and seizures, and the child's mother had valproate therapy during the pregnancy.

Lactate levels ranged from 1.8 to $7.9 \mathrm{mmol} / \mathrm{L}$ (RR $0.2-2.0$ $\mathrm{mmol} / \mathrm{L}$ ). MRI showed only microcephaly.

Liver respiratory chain enzymes at age 2 years revealed low complex IV activity of 0.2 (RR 1.1-1.6) $\mathrm{nmol} / \mathrm{min} / \mathrm{mg}$ and ratio to citrate synthase (x1000) of 4 (RR 27-48). Muscle respiratory chain enzymes were normal. This child was diagnosed with a definite mitochondrial respiratory chain (RC) disorder based on Bernier criteria (1)

Dysmorphic features became more pronounced and at age five years a 22q11.2 deletion was identified. Array studies confirmed adjacent segmental uniparental isodisomy. The mitochondrial transporter genes SLC25A18 and SLC25A1 are in this region. The finding of the 22q11.2 deletion demotes the possibility of a mitochondrial RC disorder to probable under the Bernier criteria (1).

The importance of continuing to consider other possible diagnoses even in the presence of a "definite" diagnosis of a mitochondrial disorder is stressed. The possibility that the complex IV deficiency may be secondary to genetic changes, either within the deleted region or adjacent area of uniparental heterodisomy, remains.

1. Bernier F, Boneh A, Dennett X, Chow C, Cleary M, Thorburn D (2002) Diagnostic criteria for respiratory chain disorders in adults and children. Neurology 59:1406-1411

\section{CHALLENGES IN SUPPLYING AND MANAGING A LOW PROTEIN DIET FOR THE POSTPARTUM PERIOD IN ORNITHINE TRANSCARBAMYLASE DEFICIENCY HETEROZYGOTES}

M. Tam ', M. Tchan' ${ }^{2}$, G. Mulvany ${ }^{3}$, M. Westbrook ${ }^{2}$

${ }^{1}$ Nutrition and Dietetics Department, Prince of Wales Hospital, Sydney, Australia

${ }^{2}$ Genetic Medicine, Westmead Hospital, Sydney, Australia

${ }^{3}$ Nutrition and Dietetics Department, Royal Hospital for Women, Sydney Australia

*This information was correct at the time of printing and is subject to change. 
OTC heterozygotes are variably symptomatic, but are usually managed with only mild dietary protein restrictions. In contrast, females with OTC risk elevated ammonia levels during pregnancy, labour and for 1-2 weeks after giving birth. Our patient developed hyperammonemia requiring dietary and medical managment on the second day post-partum. The report discusses the issues involved in implementing a very low or minimal protein diet, as well as dietary management during labour and the days post birth.

The major logistical dietary challenge stemmed from the increasingly common practice for hospital foods to be pre- prepared in bulk in a central location then transported to cater for a number of different hospitals. The hospital menu is also made up of a high proportion commercially prepared/ packaged foods. For this reason, hospital menus are often inflexible and it is difficult to cater to new diets from existing menu items, including a zero protein or minimal protein diet. Even though it is not often required, it is essential that all hospitals are able to provide the low protein diet that is fundamental in the management of critical illness in many metabolic genetic, disorders including the days immediately post birth in OTC pregnancies.

\section{REVIEW OF PATIENTS ATTENDING FOR THE FIRST TWELVE MONTHS OF AN EXPANDED ADULT GENETIC METABOLIC DISORDERS SERVICE}

M. Tchan', M. Westbrook

Genetic Medicine, Westmead Hospital, Westmead NSW Australia

In January 2011 an expanded Adult Genetic Metabolic Disorders Service was launched within the newly established Department of Genetic Medicine at Westmead Hospital. Staff includes a full time Clinical Geneticist, part-time medical registrar and 2 part time dietitians. The service includes a newly established clinic at a second tertiary hospital and outreach service to a regional city, Newcastle.

Throughout 2011 a database was compiled of former Westmead Hospital clinic patients, current and former patients of The Children's' Hospital at Westmead and their regional outreach service who would be over 18 years by December 2011 and new referrals. The patients' appointment dates and attendance were recorded.

A 12 months review was undertaken to identify patients not seen yet and to assess - age distribution and gender mix of the total and the attending patients, the reach of the service, and the re-attendance rate of adults who had not attended a genetic metabolic clinic for 2 years or more.

The results were collated for patients with Phenylketonuria (PKU) and other inborn errors of metabolism (IEMs) separately. $51 \%$ of the patients with PKU on the database and $68 \%$ of the patients with IBEMs attended in 2011 and of these $26.5 \%$ of PKU patients and $11.3 \%$ of the IEMs patients had returned after being lost to follow up. Attendance was higher in women and in the 18-25 and over 45 age groups. Patients who did not attend in 2011, especially those with Galactosemia, Homocystinuria and women with PKU are being encouraged to attend in 2012.

\section{OBESITY IN ADULT PATIENTS WITH PHENYLKETONURIA E. Clover', I. Chapman ${ }^{2}$, J. Fletcher ${ }^{3}$}

${ }^{1}$ Clinical Dietitian, Department of Clinical Dietetics, Royal Adelaide Hospital, Adelaide, Australia,

${ }^{2}$ Division of Medicine, University of Adelaide, Adelaide, Australia

${ }^{3}$ Clinical Director, Genetics and Molecular Pathology, SA Pathology, Adelaide Australia

Background: Evidence suggests children with phenylketonuria (PKU) weigh more than children without PKU. A tendency towards excessive weight gain has been shown in PKU adolescents. Little is known about the weight status of adults with PKU. In Australia, as in other countries, obesity rates are escalating. Associated medical complications are a growing public health concern.

Aim: To evaluate the rates of overweight and obesity in adults with PKU.
Subjects: Adults with PKU diagnosed either via newborn screening (NBS) or late, following a restricted protein diet and taking a phenylalanine free supplement, seen at the Royal Adelaide Hospital metabolic clinic in the previous 4 years were included in the audit.

Methods: Weights and heights were taken from medical records. 12 month average phenylalanine levels were calculated. Overweight and obesity rates were compared to national general population data. Available fasting blood glucose levels and lipid profiles were reviewed.

Results: 31 adults (21 NBS) were included in the audit. PKU adults had higher rates of obesity (45\% vs.18 to $21 \%$ ) and lower rates of overweight (19\% vs. $40 \%$ ) compared to the general population. Weight status was not significantly associated with average phenylalanine levels or time of PKU diagnosis. Limited data raise the possibility that obese related metabolic complications in this group are lower than expected.

Conclusion: This adult PKU population had high rates of obesity, the cause of which needs to be explored. The characteristics of the diet for PKU means investigating obese related metabolic complications in this group may be of interest.

\section{THE EFFECT OF CONTINUOUS HAEMODIAFILTRATION AND INTERMITTENT HAEMODIALYSIS ON PLASMA AMINO ACID AND AMMONIA PROFILES FOR THE METABOLIC PATIENT}

A. Elliott ${ }^{1}$, F. Bowling ${ }^{2}$, A. McWhinney ${ }^{3}$, J. McGill ${ }^{4}$

${ }^{1}$ Department of Nutrition \& Dietetics, Mater Children's Hospital, Brisbane, Queensland,

${ }^{2}$ Director of Biochemical Diseases, Mater Children's Hospital, Brisbane Queensland, ${ }^{3}$ Department of Pathology, Mater Health Services, Brisbane, Queensland, ${ }^{4}$ Director, Department of Metabolic Medicine, Royal Children's Hospital, Brisbane, Oueensland

Modern management of inborn errors of metabolism may involve the use of haemofiltration during episodes of acute metabolic decompensation and as supportive therapy for patients with acute or chronic renal failure (CRF). We describe the effect on plasma amino acid (PAA) profiles and ammonia levels during five episodes of acute decompensation based on a retrospective data review of four patients admitted to the paediatric intensive care setting and receiving continuous veno venous haemodiafiltration. We also describe the effect of intermittent haemodialysis on PAA profiles pre and post dialysis for one patient with Methyl Malonic Acidaemia and CRF receiving haemodialysis while awaiting renal transplant.

PAA and ammonia levels collected were compared to age appropriate reference ranges to examine response to filtration and dialysis. Data analysed included levels taken prior to, during and post renal replacement therapy. Concurrent nutrition therapy at time of blood collection was also examined. Pathology collection time points were not standardised for each individual. Preliminary data suggests frequent variation in individual PAA levels of $>40 \%$ particularly for the branched chain amino acids. Variation of up to $80 \%$ for certain amino acids was observed suggesting the importance of timely, appropriate concurrent nutritional therapy.

The results arising from this review will provide a greater understanding about the role of haemodiafiltration and haemodialysis on PAA and ammonia levels. This may influence clinical decision making around medical and nutritional management. Future investigations using standardised time points for blood collection would further improve the interpretation of results and their application to clinical practice.

7. UNUSUAL RADIOGRAPHIC FEATURES OF A 9 YEAR OLD GIRL WITH ATTENUATED MUCOPOLYSACCHARIDOSIS TYPE VI

Inwood $\mathrm{A}^{\prime}, \mathrm{McC}$ reanor $\mathrm{J}^{2}$, Donoghue $\mathrm{S}^{1}$, Zankl $\mathrm{A}^{3}, \mathrm{Cramb} \mathrm{J}^{4}$, Chin $\mathrm{S}^{5}$, Williams $S^{5}$, Fietz $M^{5}$, Broe $D^{6}$, McGill J' 


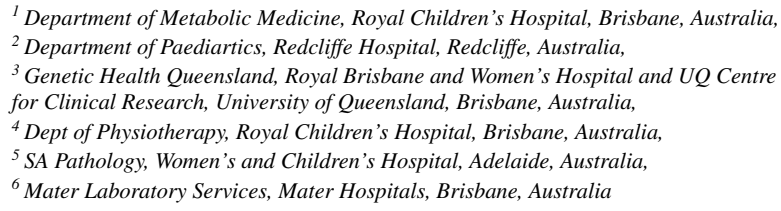

A nine-year old Caucasian girl presented with a reduced range of shoulder movement interfering with swimming and moderate lumbar scoliosis. She is born to non-consanguineous parents. Her facies, intelligence and stature are normal. Her sleep is marked by snoring without apnoea. She has a moderate reduction in shoulder range of movement with flexion (Lt \& Rt $120^{\circ}$ (normal $180^{\circ}$ )), abduction $\left(\mathrm{Lt} 100^{\circ}\right.$ - Rt $115^{\circ}\left(\right.$ normal $\left.180^{\circ}\right)$ ) and internal rotation $\left(\mathrm{Lt} 45^{\circ}\right.$ Rt $25^{\circ}$ (normal $65-90^{\circ}$ )) but normal range of movement in all other joints. Cardiac examination showed mild aortic valve thickening with 1-2/4 incompetence and mild mitral valve leaflet prolapse with no incompetence. She has mild to moderate bilateral corneal clouding. Skeletal survey revealed marked metaphyseal changes which are not a well recognised feature of MPS VI or any other lysosomal storage disorder and shortened distal phalanges. Mild radiographic signs of dysostosis multiplex of tubular bones were noted. She has dysplastic vertebral bodies with no hook-shaped vertebrae. Her sella is large but not J-shaped. Her pelvis is typical for MPS and proximal femoral epiphyses are dysplastic and fragmented. She has no hepatosplenomegaly, no hernia and no pectus deformity. Her 6 minute walk test was 590 metres, which is $>95^{\text {th }}$ centile for age. The diagnosis of MPS VI was confirmed on glycosaminoglycan quantitation (20mg/mmol creatinine, NR 4-12), MPS electrophoresis (increased dermatan sulphate bands), and $\mathrm{N}$-acetylgalactosamine-4-sulphatase activity $(<0.1 \mathrm{pmol} / \mathrm{min} / \mathrm{mg}$ protein, NR $1.5-21.0)$.

The diagnosis of a lysosomal storage disorder should be considered in children presenting with a metaphyseal dysplasia.

\section{OTC - ENERGY AND PROTEIN REQUIREMENTS OF A 2 YEAR OLD NOUMEAN GIRL PRESENTING WITH UNSTABLE AMMONIUM LEVELS}

B. Dennison', S. Brown', S. Thompson ${ }^{2}$, J. Christodoulou ${ }^{2,3}$, C. Ellaway ${ }^{2}$,

I. Alexander ${ }^{4}$, T. Dalkeith ${ }^{2}$, K. Bhattacharya ${ }^{2}$

${ }^{1}$ Nutrition and Dietetics, Children's Hospital at Westmead, Westmead, NSW, Australia ${ }^{2}$ Western Sydney Genetics Programme, Children's Hospital at Westmead, Westmead, NSW, Australia

${ }^{3}$ Paediatrics and Child Health, and Genetic Medicine, Faculty of Medicine, University of Sydney, NSW, Australia

${ }^{4}$ Gene Therapy Research Unit, Children's Medical Research Institute, Children's Hospital at Westmead, NSW, Australia

A 2.3 year old Noumean girl was admitted to The Children's Hospital at Westmead (CHW), for assessment of repeated episodes of hyperammonaemia and frequent admissions to hospital in Noumea. She was diagnosed 2 years prior with an undefined urea cycle disorder during an admission to $\mathrm{CHW}$, and was discharged home with feeding plans for health and sickness.

During this recent admission she had 3 episodes of elevated plasma ammonia of $253,284,251 \mu \mathrm{mol} / \mathrm{L}(10-50)$. Urinary orotic acid of $182 \mu \mathrm{mol} / \mathrm{L}(0.3-3.0)$ was found during one such episode, and glutamine of $1749 \mu \mathrm{mol} / \mathrm{L}$ (385-862). Ornithine Transcarbamlyase Deficiency (OTC) was provisionally diagnosed, pending confirmation by gene sequencing. She has gross motor and language delay.

On referral, it was noted she was taking $0.6 \mathrm{~g}$ protein $/ \mathrm{kg} /$ day and about $800 \mathrm{Cal} /$ day. During admission to CHW she needed $1.5 \mathrm{~g}$ protein $/ \mathrm{kg} /$ day and $90 \mathrm{Cal} / \mathrm{kg} /$ day to reach desired levels of plasma amino acids and stable ammonium. A late evening and early morning feed of Energivit ${ }^{\circledR}$ was needed to maintain equilibrium. During intercurrent illness the energy requirement increased to $120 \mathrm{Cal} / \mathrm{kg}$ and natural protein was stopped for 24 hours, grading up to about half protein Day 2 and full protein Day 3. Because she refused to eat and drink consistently well, a gastrostomy button was inserted.

Her mother was taught to provide sufficient energy and protein, using photos of $1 \mathrm{~g}$ equivalent foods commonly available in her village context. Energivit ${ }^{\circledR}$ is funded by CAFAT.

This girl with OTC requires sufficient protein, and energy fed day and night to attain metabolic stability.

\section{9. 'NO THANKS' - WHY PREGNANT WOMEN CHOOSE NOT TO HAVE CYSTIC FIBROSIS CARRIER SCREENING}

\author{
L. loannou $^{1,2}{ }^{\prime}$, J. Massie ${ }^{3,4}$, S. Lewis ', B. McClaren', V. Collins', \\ M. B. Delatycki ${ }^{1,2,4,5}$ \\ ${ }^{1}$ Murdoch Childrens Research Institute, \\ ${ }^{2}$ Department of Medicine, Monash University, \\ ${ }^{3}$ Department of Respiratory Medicine, Royal Children's Hospital, \\ ${ }^{4}$ Department of Paediatrics, University of Melbourne \\ ${ }^{5}$ Clinical Genetics, Austin Health
}

A population-based cystic fibrosis $(\mathrm{CF})$ carrier screening program was introduced in Victoria, Australia in 2006. It is offered for a fee by doctors to couples planning a pregnancy or in early pregnancy. The aim of this study was to assess the attitudes and opinions of women declining screening and compare these to those of individuals who accepted screening.

Between December 2009 and May 2011, women who declined a direct offer of $\mathrm{CF}$ carrier screening by their obstetrician were invited to participate in a questionnaire study.

A total of 50 completed questionnaires were received. The majority of participants were aged 30-34 (54\%), Twenty-five participants (51\%) answered 6 to 10 of the 15 knowledge questions correctly; however $29(59 \%)$ incorrectly believed that couples who have a child with CF usually have a family history of the condition. The main reasons for declining screening were having no family history of $\mathrm{CF}$ and would not consider a termination of pregnancy for CF. Having a family history of $\mathrm{CF}\left(\chi^{2}=54.86, \mathrm{p}<0.01\right)$ or other genetic conditions $\left(\chi^{2}=53.68, \mathrm{p}<0.01\right)$ had a significantly greater influence on the decision whether to have screening, for those who declined screening, compared to those who accepted it. Almost all of the women who participated $(96 \%)$ believe that CF carrier screening should be available to those who wish to be screened.

It is important that the community is educated that most children born with autosomal recessive conditions such as CF do not have a family history of the condition.

10. CURRENT TRENDS IN NEWBORN SCREENING REFUSAL

R. Junek', B. Wilcken ${ }^{1,2}$, V. Wiley,2

${ }^{I}$ The NSW Newborn Screening Programme, Sydney, New South Wales,

${ }^{2}$ The University of Sydney, Sydney, New South Wales

The NSW Newborn Screening Programme offers screening for over 30 different disorders of metabolism aiming to detect those babies who are most likely to have a disorder, referring them for diagnosis and treatment, thereby minimising negative consequences for the babies and their families. Newborn screening is offered to all babies born in New South Wales and Australian Capital Territory but is not mandatory. Parents who refuse to have the newborn screening dried blood spot sample collected are asked to sign a disclaimer and complete a refusal form for information. There were 147 questionnaires returned to the newborn screening programme from 2004 2011. This poster shows the statistics collected from these and the reasons given for refusal. The overall refusal rate has remained low each year ranging from $0.06 \%$ to $0.09 \%$. Of those parents completing the refusal questionnaire, $>60 \%$ have tertiary education. The demographics are not spread evenly across the state with the highest concentration of refusals in the north eastern corner, possibly 
reflecting higher numbers of families living alternative lifestyles. The poster examines the most common reasons for refusal with concerns about the storage of the samples, and believing the test to be unnecessary, being recurring themes. Almost $80 \%$ of parents returning questionnaires indicated they received verbal and written information about the newborn screening process, with only $2 \%$ saying they received no information and $>85 \%$ said English was their first language. Together these suggest that lack of information from the Programme is not a contributing factor to their decision.

\section{SCREENING FOR THE OTHER KNOWN CYSTIC FIBROSIS MUTATIONS ON THE LIGHTSCANNER}

W T Kim², V. Wiley',2

${ }^{1}$ Discipline of Paediatrics and Child Health, University of Sydney,

${ }^{2}$ NSW Newborn Screening Programme, The Children's Hospital at Westmead, Sydney, Australia.

Background: Cystic Fibrosis (CF) is the most common disorder screened by the NSW Newborn Screening Programme (incidence 1:3000 live births). The most common mutation detected on at least one allele in over $90 \%$ of patients is p.F508del. However, $40 \%$ of $\mathrm{CF}$ babies are compound heterozygotes with a second mutation such as p.G551D and p.G542X. As CF symptoms can develop early, methods to reduce the time to treatment are required.

In NSW, high-resolution melting (HRM) analysis was evaluated for detection of CF mutations in dried blood spots and compared with the current size exclusion gel electrophoresis method.

Method: There were 1251 samples assessed for mutational analysis in 2011. Samples were extracted and transferred into the wells on a PCR plate where they were amplified using a thermal cycler. The amplified products were loaded into the Lightscanner. HRM of nucleic acid detects high-density information of melting temperature (fluorescence) in a mixture of a double-strand DNA binding dye and PCR product. Melting curve results were analysed by Lightscanner software program.

Result: In 2011 there were 24 babies diagnosed with CF, 13 babies homozygous for p.F508del and 69 with one copy, 11 of whom had CF. One baby was detected with p.G551D. Both methods showed comparable results.

Conclusion: The Lightscanner provides higher sample capacity, detection of additional mutations, and has less turnaround time allowing faster time to treatment for babies with CF.

\section{SIGNATURE PEPTIDES AS BIOMARKERS FOR THE IDENTIFICATION OF HAEMOGLOBINOPATHIES}

\section{A. Alam ${ }^{1,2}$, R.I. Boysen', D.K. Bowden ${ }^{1,2}$, M.T.W. Hearn' \\ ${ }^{1}$ ARC Special Research Centre for Green Chemistry, Monash University, Victoria, Australia, \\ ${ }^{2}$ Clinical Genetics Laboratory, Monash Medical Centre, Southern Health, Melbourne, Australia}

Haemoglobinopathies are autosomal recessive disorders. They are the most common human single-gene disorders and are associated with abnormal globin gene expression, which results in either changes in the quantitative production of the globin chains or their structural aberrations. The majority of amino acid sequence variations are caused by a small number of frequently occurring mutations often with very high regional/ethnic human population dependencies. Pre- and postnatal screening programs are essential for effective diagnosis, counselling, and clinical management of individuals and their families exhibiting haemoglobinopathies. Mass spectrometry is a powerful tool for diagnostic screening programs, but its use for clinical haemoglobinopathy assessment has not been implemented in Australia. This investigation was focused on establishing analytical methods, which allow the unambiguous identification of haemoglobin variants through unique and diagnostically relevant methods for the identification of haemoglobin variant 'signature' peptide(s). In this work, sensitive and rapid analytical methods have been developed for the detection of human haemoglobin disorders using very small volumes $(<1 \mu \mathrm{L})$ of blood. As an alternative to conventional enzymatic digestion, surfactant-aided enzymatic and microwave-assisted site-specific chemical cleavage methods have been established which allow very rapid proteolysis in less than $10 \mathrm{~min}$. These methods have been applied to fifteen haemoglobin variants with identification of the corresponding haemoglobin variant 'signature' peptides by mass spectrometry. These microwaveassisted and MS-compatible sample preparation methods are expected to significantly contribute to the development of rapid, robust, cost-effective and environmentally benign methods of haemoglobin analysis in population screening studies.

\section{THE AUSTRALIAN FAMILIAL PANCREATIC CANCER COHORT: SCREENING FOR PANCREATIC CANCER IN HIGH RISK AUSTRALIANS}

S. Simpson' ', A. Johns' , A. Spigelman ${ }^{2}$, D. Williams ${ }^{3}$, A. Stoita ${ }^{3}$, K. Tucker ${ }^{4}$, J. Kirk ${ }^{5}$, M. Field ${ }^{6}$, R. Williams ${ }^{4}$, A. Goodwin ${ }^{5}$, S. Grimmond ${ }^{7}$, J. Humphris ${ }^{1}$, S. Mead', D. Chang', A. Biankin'

${ }^{1}$ Cancer Research Program, Kinghorn Cancer Centre/Garvan Institute of Medical Research, Darlinghurst, NSW, Australia

${ }^{2}$ Familial Cancer Clinic, Kinghorn Cancer Centre/St Vincent's Hospital, Darlinghurst, NSW, Australia

${ }^{3}$ Gastroenterology, St Vincent's Hospital, Darlinghurst, NSW, Australia

${ }^{4}$ Hereditary Cancer Clinic, Prince of Wales Hospital, Randwick, NSW, Australia

${ }^{5}$ Familial Cancer Service, Westmead Hospital, Westmead, NSW, Australia

${ }^{6}$ Familial Cancer Service, Royal North Shore Hospital, St Leonards, NSW, Australia

${ }^{7}$ Queensland Centre for Medical Genomics, Institute for Molecular Bioscience, St Lucia, QLD, Australia

The majority of pancreatic cancer cases are termed sporadic, although it is estimated that $10 \%$ are familial. Known genetic conditions account for less than $20 \%$ of this familial aggregation [1]. The predisposing genetic basis for most families with a clustering of pancreatic cancers is unspecified, and the predicted risks to unaffected family member can be ambiguous [2].

Multiple international familial pancreatic cancer registries are utilising genome sequencing to collaboratively identify novel pancreatic cancer susceptibility genes, such as PALB2 [3], however more needs to be known about the predisposing genetic aspects of pancreatic cancer in Australian families.

The Australian Familial Pancreatic Cancer Cohort (AFPaCC) is a recently established registry targeting families or individuals with a history of pancreatic cancer. Registration involves consent, and collation of relevant clinical information. A blood sample is collected to search for additional pancreatic cancer susceptibility genes. Recruitment will use a multi-centred approach, with individuals identified through Family Cancer Clinics, treatment centres, cancer registries or directly by clinicians and our website. AFPaCC will also help to identify high-risk individuals who may benefit from screening trials.

The overall aims of AFPaCC are to further clarify the risk in families with a history of pancreatic cancer in Australia and discover genetic and non-genetic causes of pancreatic cancer. Although AF$\mathrm{PaCC}$ is still in it's infancy, this poster aims to raise awareness of the project, provide contact details and give an initial overview of the Australian families already involved.

[1] Shi C, Hruban RH, Klein AP. Familial pancreatic cancer. Arch Pathol Lab Med 2009 March; 133(3):365-374

[2] Permuth-Wey J, Egan KM. Family history is a significant risk factor for pancreatic cancer: results from a systematic review and meta-analysis. Familial Cancer 2009;8(2):109-117 
[3] Jones S, Hruban RH, Kamiyama M et al. Exomic sequencing Identifies PALB2 as a pancreatic cancer susceptibility gene. Science 2009;324:217

\section{ONCOLOGY HEALTH PROFESSIONALS' ATTITUDES TOWARDS TREATMENT FOCUSED GENETIC TESTING}

S. Burcher' , B. Meiser ${ }^{2}$, K. Barlow-Stewart I, 3, B. Rahman'2, K. Tucker ${ }^{4}$, G. Mitchell ${ }^{5}$, J. Kirk ${ }^{6}$, C. Saunders ${ }^{7}$

${ }^{I}$ Sydney Medical School, The University of Sydney, Sydney, NSW,

${ }^{2}$ Psychosocial Research Group, Prince of Wales Clinical School, UNSW, Sydney, NSW,

${ }^{3}$ The Centre for Genetics Education, NSW Health, Sydney, NSW,

${ }^{4}$ Hereditary Cancer Clinic, Prince of Wales Hospital, Sydney, NSW,

${ }^{5}$ Familial Cancer Centre, Peter MacCallum Cancer Centre, Melbourne, VIC,

${ }^{6}$ Familial Cancer Service, Westmead Hospital, Sydney, NSW,

${ }^{7}$ School of Surgery and Pathology, University of Western Australia, Nedlands, WA

Significant advances have been made in our understanding of the underlying genetic causes of breast cancer, and two genes, BRCA1 and BRCA2, have been identified as breast cancer protection genes. A mutation in one of these genes can lead to an increased risk of breast and/or ovarian cancer. A new approach to breast cancer care has been developed called treatment focused genetic testing (TFGT). It involves a genetic test done around the time a woman is diagnosed with cancer to help her and her doctor decide on the best treatment plan. As this is a new approach, little is known about its overall effectiveness and clinicians' attitudes towards TFGT. The aim of this ongoing project is to investigate the attitudes and experiences of oncology health professionals towards TFGT of women newly diagnosed with breast cancer. A web based survey that aims to elicit responses addressing this research question has been developed using existing attitude measures as well as novel questions. Participants will include surgeons, radiation and medical oncologists, clinical geneticists and breast care nurses, and they will be recruited through several relevant professional organisations. It is hoped that the findings from this study will be used to guide the integration of TFGT into the health care of women with breast cancer.

\section{SEQUENCE ANALYSIS OF THE NEMO GENE IN A COHORT OF PATIENTS WITHOUT THE COMMON NEMO $\triangle$ 4-10 DELETION}

L. Sanchez', E. Douglas', R. Catford', E. Haan², L. McGregor², K. Friend'

'Diagnostic Molecular Genetics Unit, SA Pathology at the Women's and Children's Hospital, North Adelaide, SA.

${ }^{2}$ SA Clinical Genetics Service, SA Pathology at the Women's and Children's Hospital, North Adelaide, SA.

Incontinentia Pigmenti (IP) is an X-linked inherited disorder associated with mutations in the IKBKG gene (also called NEMO). It is typically male lethal, while female carriers usually develop characteristic skin lesions in early infancy. Other common features include missing or abnormally shaped teeth and cicatricial alopecia of the scalp. More severe clinical manifestations may include intellectual disability, seizures, cataracts and optic atrophy. A loss of function mutation of the $N E M O$ gene $(N E M O \triangle 4-10 \mathrm{del})$ is responsible for the majority of IP cases $(\sim 70-80 \%)$, while other sequence variants account for a small percentage of cases.

We have sequenced all exons, and flanking intronic regions, of the $N E M O$ gene in 7 cases referred for IP testing for which initial analysis did not detect the common NEMO $\triangle 4-10$ deletion. Sequence variants were detected in 2 of the 7 cases. A variant in intron 8 (c.1056-18C $>\mathrm{T})$ was detected in a 3 month old girl presenting with characteristic skin lesions but no other features of IP. RNA studies did not reveal any evidence of altered splicing.

A truncation mutation in exon 3 (c.199C $>$ T) was identified in a family where two maternal half sisters had presented with clinical signs of IP. Sequencing of DNA from maternal blood revealed the presence of this mutation, but the amplitude of the wildtype and mutant alleles were suggestive of mosaicism. This was confirmed by cloning studies which estimated the frequency of the mutant allele to be $23 \%$ in blood lymphocytes, $36 \%$ in hair follicle cells and $33 \%$ in buccal cells.

\section{HAEMOGLOBIN E AND CO-EXISTING ALPHA THALASSAEMIA IN THE SOUTH AUSTRALIAN POPULATION}

Nguyen ', C. Nicholls' $^{\text {, M. Holloway', A. Simsek' , A. Griffiths }}{ }^{2}$, H. Scott'

${ }^{1}$ Molecular Genetics Laboratory, Department of Molecular Pathology, SA Pathology, Frome Rd Adelaide, South Australia.

${ }^{2}$ Automated Haematology, SA Pathology, Frome Rd, Adelaide South Australia

Background:Haemoglobin E (HbE, HBB:c.79G > A) is a common haemoglobinopathy in the South Australian population. This mutation creates an alternative splice leading to reduced synthesis of the haemoglobin beta (HBB) gene. Heterozygotes are asymptomatic with homozygotes having mild haemeolytic anaemia and microcytosis. From a clinical perspective, the importance of $\mathrm{HbE}$ is its interaction with alpha and beta thalassaemias where it can lead to $\mathrm{HbE} /$ thalassaemia syndromes of varying severity. The aim of the present study was to review the South Australian patient population to ascertain the percentage patients with $\mathrm{HbE}$ who have co-existing alpha thalassaemia.

Methods. 53 patients with HbE identified by HPLC have had confirmation by sequencing of the entire coding region splice junctions and promoter regions of the HBB gene. The Haemoglobin alpha gene was screened for common deletions using gap PCR.

Results and Discussion: 35/53 patients were heterozygotes and 18/53 homozygotes for $\mathrm{HbE}$.

$31 / 53$ (21/31 heterozygotes and 10/31 homozygotes) patients were screened for the common deletions in the haemoglobin alpha gene, with $7 / 31(23 \%, 5 / 7$ heterozygotes and $2 / 7$ homozygotes) found to have co-existing mutations in the haemoglobin alpha genes. Both $\mathrm{HbE}$ homozygotes had a single alpha gene deletion $(3.7 \mathrm{kB})$ with $\% \mathrm{HbE}$ of 82.3 and 80.3. The $5 \mathrm{HbE}$ heterozygotes had varied results with $\mathrm{HbE}$ ranging from $15.5 \%$ in a patient with 3 haemoglobin alpha genes deleted to $68.9 \%$ in a beta0/HbE compound heterozygote with one haemoglobin alpha gene deleted.

Conclusion: Approximately $1 / 5$ patients with $\mathrm{HbE}$ had coexisting alpha thalassaemia. A strategy for molecular screening for co-existing alpha thalassaemia will be discussed.

\section{WHEN SIZE DOES MATTER}

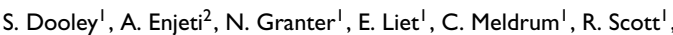
S. Way'

${ }^{1}$ Genetics Department, Hunter Area Pathology Service, John Hunter Hospital, New Lambton, NSW, Australia

${ }^{2}$ Haematology Department, Calvary Mater Hospital, Waratah, NSW, Australia

In May 2009 HAPS Genetics Department \& the Dept of Haematology $\mathrm{CMH}$ investigated the feasibility of introducing quantitative BCR-ABL testing in this laboratory. We initially trialed an in-house method based on 96 well plates using ABI 7900 Real time PCR.

In March 2010 we commenced trials of the GeneXpert BCRABL monitor kit from Diagnostic Technology. This is a cartridge based assay that performs RNA extraction, cDNA production, nested real-time PCR and signal detection in a single cartridge.

Our laboratory chose the GeneXpert because of its ease of operation and quick turnaround time. The advantages and disadvantages of both methods are discussed.

We collected samples for the international standardization programme and completed standardization and validation of our testing procedure in June 2011. Our correction factor was determined as 
0.43. We commenced offering $q B C R-A B L$ testing as a service in September 2011.

Ironically, Cepheid - the manufacturing company of GeneXpert, were also completing standardization and validation procedures and in late September 2011 introduced a software upgrade and cartridge series which incorporated their correction factor. Their correction factor was determined as $\mathbf{0 . 4 7}$.

The similarity of the 2 correction factors is indicative of the uniformity of the cartridges and of the method of RNA extraction and quantitation in the GeneXpert.

Over the last 6 months we have tested 167 patient samples. Of these 5 required repeat analysis and all produced an acceptable result.

We have found the GeneXpert BCR-ABL monitor kit to be easy to use, giving results within 2 hours of sample arrival.

\section{MITOCHONDRIAL COMPLEX III DEFICIENCY} ASSOCIATED WITH A HOMOZYGOUS MUTATION IN TTC19

S. Balasubramaniam' ', S. Oates', A. Jolley ${ }^{2}$, J. Nicholl ${ }^{2}$, D. Kettridge', S. Yu ${ }^{2}$, D. Bratkovic ${ }^{\prime}$

${ }^{1}$ Metabolic Clinic, Genetics and Molecular Pathology, SA Pathology, Adelaide, Australia,

${ }^{2}$ Molecular Genetics Unit, Genetics and Molecular Pathology, SA Pathology, Adelaide, Australia

Isolated mitochondrial respiratory chain Complex III deficiency has been described in a heterogenous group of neuromuscular and non neuromuscular disorders in children and adults. CYTB is the only mitochondrial DNA encoded subunit, whereas nuclear mutations have been identified in 4 genes thus far: BCS1L, UQCRB, UQCRQ and most recently TTC19 on chromosome $17 \mathrm{p} 12$. Here we report an 8-year-old girl born to consanguineous Iraqi parents presenting with a slowly progressive encephalomyopathy, defects in verbal and communicative skills and severe failure to thrive. Metabolic work up was normal including blood and CSF lactate levels. Brain magnetic resonance imaging showed bilateral hyperintensities in the lentiform nuclei. Reduced activity specifically of mitochondrial complex III was evident on muscle biopsy. Illumina HumanCytoSNP-12 BeadChip array identified 20 regions of loss of heterozygosity $\geq 3 \mathrm{Mb}$ indicating the regions of homozygosity by decent. These include a $8.9 \mathrm{Mb}$ region on chromosome 17 , harbouring many genes including TTC19. TTC19 is a subunit of mitochondrial respiratory chain complex III which transfers electrons from coenzyme Q to cytochrome c. This electron transfer generates the mitochondrial electrochemical potential. Sequencing of all coding regions of TTC19 gene revealed a homozygous nonsense mutation in exon 6 (NM_017775.3:c.[937C > T]; [937C > T]). Both parents were heterozygous for this mutation. The $U Q C R Q$ gene which is also located in a region of $\mathrm{LOH}$ is currently being sequenced to exclude any possible mutations. This case highlights the value of SNP arrays in identifying disease loci and potential candidate genes in autosomal recessive disorders, particularly in consanguineous pedigrees.

\section{THE AUSTRALASIAN CLINIC OF GENOMIC AND PERSONALISED MEDICINE}

\section{A. Winnington', D. Samaranayake ${ }^{2}$, C. Rapsey ${ }^{2}$ \\ ${ }^{l}$ Aoraki Healthcare Limited, Timaru, New Zealand, \\ ${ }^{2}$ University of Otago, Dunedin, New Zealand}

Personalised genomics is revolutionising medicine by empowering individuals to take care of their own healthcare. The Australasian Clinic of Genomics and Personalised Medicine delivers safe, accurate and affordable genomic analysis direct to consumers. Patients referred to the clinic receive genomic analysis of polymorphisms that are statistically validated for disease phenotypes. Clinical Genomicists interpret the test results and education is provided re- garding changes in a patient's risk profile. Genomic information has been shown to enhance patient compliance with lifestyle modification recommendations, such as smoking cessation and preventing hypercholesterolemia. Accordingly preventative medical strategies personalised to individual patient's disease risk profile are provided. This presentation introduces the benefits of clinical genomics to modern healthcare and outlines the safe practice of personalised genomics within the public and private sectors.

\section{AN AUDIT OF PATIENTS WITH HEREDITARY} HEMORRHAGIC TELANGIECTASIA (HHT).

Ingrid Winship', Manju Salaria' , Jessica Taylor'

${ }^{1}$ Department of Genetic Medicine, Royal Melbourne Hospital, Grattan Street, Parkville, Melbourne, Victoria, Australia

Background: Hereditary hemorrhagic telangiectasia is a genetic disorder characterized by epistaxis, mucocutaneous telangiectasia and visceral arteriovenous malformations (AVMs), particularly in brain (CAVMs), lungs (PAVMs), liver (HAVMs) and gastrointestinal tract.

HHT is caused by mutations in $E N G$ (HHT1) and $A L K 1$ (HHT2). Recently more genes have been identified which cause HHT. One of them is SMAD4, which causes a combined syndrome of juvenile polyposis and HHT (JPHT)

Aim: The study aims to characterize phenotypic features of patients with HHT seen at our centre, to develop a protocol for surveillance in the clinic for patients with HHT.

Methods: Over the past five years, the genetic department of Royal Melbourne Hospital has become a referral centre for patients with HHT.

Patients referred with a clinical diagnosis of HHT as per Curacao criteria were included in this study. The phenotypic features and investigations of these patients were recorded in a pre-structured Performa. Encoded data was transferred from the Performa to a spreadsheet.

Data was analysed for clinical features, types of HHT, complications of HHT and genetic testing results where available. These patients were divided into subtypes, i.e. HHT1 and HHT2, and possibly in association with juvenile polyposis and JPHHT.

Results: Our cohort consisted of 40 females and 23 males referred with the diagnosis of HHT. 22 patients fulfilled the criteria for definite diagnosis of HHT, 30 were suspected HHT and 11 were unlikely to be HHT. 17 patients had pulmonary AVMs, 5 had liver AVMs, 3 had bowel telangiectasia and 1 patient had pancreatic AVMs. 2 of our patients had follow up during pregnancy. One of the pregnant female had pulmonary hypertension and second one was an adolescent with pulmonary AVMs. Both these pregnancies were successful with multidisciplinary team care.

Genetic testing was available in 20 patients with HHT; most of these were definite HHT, patients with serious clinical features of HHT or where genetic testing was required for family planning. 2 patients had mutation in $E N G$ gene, 3 had mutation in $A L K 1$ gene and 4 patients had mutation in SMAD4 gene. The patients with SMAD4 were ascertained after being diagnosed to have juvenile polyposis.

Conclusions: The patients with HHT need a multidisciplinary team approach. The initial screening to look for involvement of various organs is needed for classifying patients. With careful monitoring, the pregnancy is successful in patients with HHT. A protocol for patients with HHT was developed to streamline management of families with HHT at our centre.

25. A RETROSPECTIVE STUDY OF CANCER IN AUSTRALIAN AND NEW ZEALAND CYSTIC FIBROSIS (CF) PATIENTS

J. McGaughran', Bell. S2, J. Wilson ${ }^{3}$

${ }^{1}$ Genetic Health Queensland, Royal Brisbane \& Women's Hospital, Brisbane and UQ School of Medicine, Brisbane, Queensland Australia 
${ }^{2}$ Thoracic Medicine, The Prince Charles Hospital, Brisbane, Australia ${ }^{3}$ AIRMed, The Alfred Hospital, Melbourne, Australia

With improvements in the early diagnosis and more effective treatment of cystic fibrosis (CF) over the past 50 years, there has been a dramatic increase in survival. It is important to understand whether these patients are at risk of other complications now they are surviving longer into adulthood. Some reports have suggested an increase in bowel cancer in CF patients. There is little data available about these and other cancers occurring in CF patients in Australia and New Zealand. A questionnaire was sent out in December 2010 to Australasian adult CF Centres. The deidentified data collected included: phenotypic features of $\mathrm{CF}$, genotype of $\mathrm{CF}$, presentation with cancer, histology and site of cancer, family history of cancer, history of transplant and outcome of cancer.

Data were received for 34 patients with a total of 36 cancers/carcinomas in situ. Fifteen gastro-intestinal tract malignancies were identified. A number of other malignancies were reported including skin cancers, renal cancer and breast cancer. The age at diagnosis of cancer was between 15-56 years and all cases reported were diagnosed since 2000. All but eight patients were diagnosed with $\mathrm{CF}$ under the age of 2 years and all but two patients were pancreatic insufficient. Thirteen patients had received bilateral lung transplants and one a multiple organ transplant. Details of the cancers will be presented.

\section{UTILITY OF GENETIC TESTING IN HYPERTROPHIC CARDIOMYOPATHY IN QUEENSLAND'S STATEWIDE CARDIAC GENETICS CLINIC}

\author{
L. Hunt ', L. McCormack ${ }^{2}$, J. Atherton ${ }^{2}$, J. McGaughran' \\ ${ }^{1}$ Genetic Health Queensland, Royal Brisbane and Women's Hospital, Brisbane, \\ Australia, \\ ${ }^{2}$ Department of Cardiology, Royal Brisbane and Women's Hospital, Brisbane, Australia
}

Introduction: Genetic testing in hypertrophic cardiomyopathy (HCM) families is cost effective compared to lifelong clinical screening of at-risk relatives, but sensitive to the mutation detection rate in the proband and the number of at-risk relatives who access predictive testing. The Cardiac Genetics clinic began at the Royal Brisbane and Women's Hospital in February 2007 with genetic testing offered as part of the statewide service.

Methods: Retrospective analysis of all individuals who had diagnostic or predictive HCM genetic testing in Queensland. This determined the mutation detection rate in probands and the number of at-risk relatives who accessed predictive testing.

Results: Seventy-two probands had diagnostic testing: mutations were identified in $40(56 \%)$, no mutation in $25(34 \%)$ and variants of unknown significance in 7 (10\%). Of the 40 mutation-positive probands, 63 of their at-risk relatives underwent predictive genetic testing to determine their carrier status (1.6 relatives per mutationpositive proband). A higher proportion accessed predictive testing when the family mutation was indentified before compared with after December 2008 (2.5 vs. 0.2). An additional 29 at-risk relatives underwent predictive genetic testing where the probands genetic test was performed outside of Queensland. Forty-seven of the 92 relatives $(51 \%)$ who underwent predictive testing did not carry the family mutation and were discharged from lifelong clinical screening.

Conclusion: A mutation was identified in 56\% of HCM probands who accessed genetic testing. Predictive testing can be useful for atrisk relatives however it can take many months or years for relatives to present to clinic.

\section{MOLYBDENUM COFACTOR DEFICIENCY DUE TO MOCS2} MUTATION

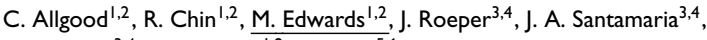
G. Schwarz ${ }^{3,4}$, J. Whitehall ${ }^{1,2}$, F. Wong ${ }^{5,6}$
${ }^{1}$ Department of Paediatrics, Campbelltown Hospital, Campbelltown, NSW, Australia ${ }^{2}$ Department of Paediatrics, School of Medicine, University of Western Sydney, Campbelltown, NSW, Australia

${ }^{3}$ Institute of Biochemistry and Center for Molecular Medicine Cologne, Germany

${ }^{4}$ University of Cologne, Germany

${ }^{5}$ Monash Newborn, Level 5, 246 Clayton Road, Clayton, VIC 3168, Australia

${ }^{6}$ Monash University, Clayton, Victoria

Molybdenum cofactor deficiency causes severe neonatal metabolic disease, seizures and death or severe brain damage. The cofactor forms the active site in aldehyde oxidase, xanthine oxidoreductase, mitochondrial amidoxime reducing component and sulphite oxidase. Cyclic pyranopterin mononophosphate (cPMP), the first intermediate in molybdenum cofactor synthesis, is absent in patients with mutations in MOCS1 gene, while it is elevated in patients with MOCS2 mutations. Mutations in MOCS1 (complementation group A) cause about $2 / 3$ of cases, and are potentially treatable with cPMP. Mutations in MOCS 2 are found in complementation group B. A mutation in the GEPHYRIN gene was found in one case in complementation group $\mathrm{C}$.

A $3.2 \mathrm{~kg}$ fullterm girl with Apgar scores 9/1,9/9, with no dysmorphic features or ectopia lentis, was well until day 2 then developed refractory seizures, opisthotonus, exaggerated startle reflexes and vomiting and died aged 7 days. Pregnancy and family history were unremarkable, one parent is of Indonesian origin, the other of southern European ancestry. MRI showed a thin corpus callosum. Uric acid levels during life and at autopsy were low and sulphocysteine and xanthine were high. The condition progressed too rapidly for empiric cPMP supplementation. Urine level of compound Z (cPMP oxidation product) was elevated. Analysis of the patient's DNA identified a previously unreported homozygous mutation in exon 4 in MOCS2, c.351 A -> G encoding an alanine for threonine substitution. Analysis of parental DNA is proceeding to clarify mechanisms, such as an undetected deletion or uniparental disomy.

\section{PRIMARY CILIARY DYSKINESIA (PCD) CAUSING IDIOPATHIC TACHYPNOEA IN NEWBORN}

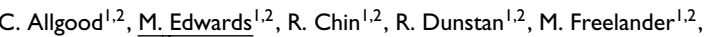 \\ L. Morgan ${ }^{3}$, J. Whitehall ${ }^{1,2}$ \\ ${ }^{1}$ Department of Paediatrics, Campbelltown Hospital, P O Box 149, Campbelltown, \\ NSW, Australia \\ ${ }^{2}$ Department of Paediatrics, School of Medicine, University of Western Sydney, Locked \\ Bag 1979, Penrith 2751, NSW, Australia \\ ${ }^{3}$ Department of Thoracic Medicine, Concord Hospital, Concord NSW 2139, Australia
}

PCD is an uncommon autosomal recessive disease, caused by mutations in various genes involving structure or function of cilia, causing impaired clearance of mucus and pathogens and chronic sinopulmonary disease. The ciliary abnormality causes random determination of situs, so $50 \%$ of patients have situs inversus/dextrocardia. A fullterm boy weighing $3725 \mathrm{gm}$ after an uncomplicated pregnancy had Apgar scores of 9/1 and 9/5. His P6 G9 mother had a cousin with dextrocardia, her family is consanguineous. No resuscitation was required, but from age 31 hours, 7 days of supplemental oxygen was needed for tachypnoea of newborn, with mucopurulent upper respiratory secretions. Chest $X$ ray showed dextrocardia and situs inversus. Echocardiography showed ASD and a small patent foramen ovale. Cilia on nasal mucosal brushings were completely immotile on light microscopy and the number of inner and outer dynein arms was markedly deficient on EM.

A younger brother was born at 24 weeks gestation weighing $596 \mathrm{gm}$ and required ventilation for a month followed by CPAP for hyaline membrane disease. He had pulmonic stenosis, patent ductus arteriosus, retinopathy of prematurity and hyperbilirubinaemia treated by phototherapy, followed by chronic conjugated hyperbilirubinaemia. A skeletal survey showed marked periostitis attributed to CMV, detected by blood PCR analysis. Plasma VLCFA pattern, urine metabolic screen, DSIDA scan and 
galactose-1-phosphate uridyl transferase level were normal, CGH pending. Antenatal screens for rubella, syphilis and HIV were negative. Although it is unknown whether ciliopathies cause periostitis or cholestasis, these could be two more conditions associated with ciliary dysfunction.

\section{NOONAN-LIKE SYNDROME WITH LOOSE ANAGEN} HAIR-A REPORT OF 2 ADULTS.

\author{
A. F. Colley, 2, M. Bakshi', 3 \\ ${ }^{I}$ Department of Clinical Genetics, Liverpool Hospital, Australia \\ ${ }^{2}$ Senior Clinical Lecturer, University of NSW \\ ${ }^{3}$ Discipline of Paediatrics and Child health, University of Sydney, Australia.
}

Noonan-like syndrome with loose anagen hair was described by Mazzanti et al in 2003. SHOC2 mutations have recently been documented in patients with this disorder. The childhood phenotype is relatively well described. Here we describe 2 adults with identical heterozygous SHOC2 mutations (p.Ser2Gly). They share some clinical features such as distinctive facial appearance with easily pluckable hair, short stature, prematurely aged look, moderate intellectual disability and immature pubertal development. In addition, patient 1(31 year old female) developed gait disturbance in adulthood with pyramidal signs in the lower limbs. Patient 2(19 year old female) has mitral valve prolapse, seizure disorder, congenital nystagmus, protein losing enteropathy and immune dysfunction.

30. FROM INFANCY TO ADULTHOOD - A COSTELLO SYNDROME STORY IN PICTURES

A.F Colley ${ }^{1,2}$, M. Bakshi $^{1,3}$

${ }^{1}$ Department of Clinical Genetics, Liverpool Hospital, Australia,

${ }^{2}$ Senior Clinical Lecturer, University of NSW, Australia,

${ }^{3}$ Discipline of Paediatrics and Child Health, University of Sydney, Australia.

Costello syndrome is a disorder of the RAS-MAPK pathway due to mutations in the HRAS oncogene. Costello syndrome is characterised by moderate to severe intellectual disability, short stature, distinctive coarse facial features, cardiac abnormalities and increased susceptibility to childhood malignancy. Here we present a lady with Costello syndrome, her evolving phenotype from infancy to adulthood and a clinical description of associated health complications. Physical features in infancy characterised by woolly slow growing hair, thick lips with wide mouth, cutis laxa of hands and feet; facial papillomata with progressive coarsening of facial features in childhood and short stature with a prematurely aged appearance in adulthood will be demonstrated pictorially.

\section{A FAMILY WITH AN ARG134CYS MUTATION IN COL1A1 AND OVERLAPPING PHENOTYPES OF OTEOGENESIS IMPERFECTA AND EHLERS-DANLOS SYNDROME}

E.M Thompson' ${ }^{\text {, E. Tham }}{ }^{2}$, J. Bradley ${ }^{3}$, K. Friend ${ }^{4}$

${ }^{1}$ SA Clinical Genetics Service, SA Pathology at the Women's and Children's Hospital, North Adelaide, Australia

${ }^{2}$ Endocrinology and Diabetes Centre, Women's and Children's Hospital, North Adelaide, Australia

${ }^{3}$ Adelaide Cardiology, 270 Wakefield Street, Adelaide, Australia

${ }^{4}$ Diagnostic Molecular Genetics Unit, SA Pathology at the Women's and Children's Hospital, North Adelaide, Australia

The female proband presented at 10 months of age with fractures after no known injury and was diagnosed with osteogenesis imperfecta. She scored 6/9 on the Beighton scale of hyperextensibility. She was treated with regular intravenous bisphosphonate infusions resulting in marked improvement in well being and development, and reduced fracture frequency.
From the age of 14 years, her father had several minor fractures never involving the long bones, usually after a significant injury. $\mathrm{He}$ had abnormal wide, atrophic scars on his legs but not particularly stretchy skin. He scored 4/9 on the Beighton scale and had early osteoporosis. He had a long history of central chest pain and reported tachycardia while cycling but cardiac investigations were normal.

DNA from the proband was analysed at Matrix DNA Diagnostics, Tulane University, New Orleans. An Arg134Cys substitution mutation was identified in COL1A1, in the highly conserved Gly$\mathrm{X}-\mathrm{Y}$ triplet. This leads to formation of abnormal aggregates of type 1 collagen molecules that cannot be secreted efficiently. The father also carries this mutation.

Mutations in type 1 collagen are mostly associated with a phenotype of osteogenesis imperfecta. However, this particular mutation was reported previously in two children with classical Ehlers-Danlos syndrome and in a woman with Ehlers-Danlos syndrome and dissection of an iliac artery. Our proband's phenotype is predominantly that of OI, whereas her father has some features of Ehlers-Danlos syndrome and a history of minor fractures. Follow up regarding the risk of arterial rupture will be important.

\section{GENOTYPE/PHENOTYPE CLASSIFICATION OF A FAMILY WITH A NOVEL MISSENSE MUTATION IN NOG, SURGICAL IMPLICATIONS FOR STAPEDECTOMY}

C. S. Manning ', D. Young ${ }^{2}$, V. Hyland ${ }^{2}$, J. MacMillan ${ }^{3}$

${ }^{1}$ South Australian Clinical Genetics, SA Pathology, North Adelaide, Australia

${ }^{2}$ Queensland Pathology, Brisbane, Australia

${ }^{3}$ Genetic Health Queensland, Queensland, Australia

Objectives:

- To describe clinical and radiologic features, results of ear surgery and genetic analysis in a family with a novel missense mutation in the $N O G$ gene.

- To review the efficacy of stapedectomy in this family.

- To consider if the phenotypic range in this family lends support for a unifying term for $N O G$ allelic syndromes.

Background: The $N O G$ gene encodes the noggin protein, which is associated with several syndromes displaying joint synostoses, stapes fixation and facial dysmorphic features. 44 mutations in this gene have been reported previously. There are four allelic NOG gene related symphalangism syndromes. The overlap between these syndromes lends weight to the proposal of a single diagnostic term: $N O G$-related Symphalangism Spectrum disorder.

Methods: I examined the available members ( 3 affected) of a family who exhibited a variable phenotype of symphalangism and stapes fixation. Reconstructive middle ear surgery was performed in two patients (four ears), and I sequenced the $N O G$ gene in the proband.

Results: Two of three affected members had conductive hearing impairment, whilst all three had symphalangism. Surgery manifested stapes ankylosis. Air-bone gaps decreased to less than $10 \mathrm{~dB}$ in two of four ears operated on. Genetic analysis revealed a novel missense mutation in the $N O G$ gene. The variant segregated with affected individuals in this family.

Conclusion: The familial novel missense mutation was not found in the 1000 genome project but segregated with affected family members thus is likely pathogenic. Reconstructive middle ear surgery can be problematic in families with a $N O G$ gene mutation. The intrafamilial variability noted in this family lends support for a single diagnostic term: $N O G$-related Symphalangism Spectrum disorder. 
33. AN ADDITIONAL CHIME SYNDROME CASE DUE TO COMPOUND HETEROZYGOUS MUTATIONS IN PIGL

S. Sandaradura', B. $\mathrm{Ng}^{2}$, H. Freeze ${ }^{2}$, D. Mowat'

${ }^{1}$ Department of Medical Genetics, Sydney Children's Hospital, Sydney, NSW, Australia ${ }^{2}$ Genetic Disease Program, Sanford Children's Health Research Center,

Sanford-Burnham Medical Research Institute, La Jolla, CA, USA

CHIME syndrome (OMIM\#280000) is a rare autosomal recessive condition characterised by ocular colobomas, congenital heart disease, early onset ichthyosiform dermatosis, mental retardation and ear anomalies, including conductive hearing loss. Eight cases have previously been described worldwide. Whole exome sequencing on five previously described cases has recently been used to identify the causative gene, PIGL. PIGL encodes N-acetylglucosaminylphosphatidylinositolde- $\mathrm{N}$-acetylase, an enzyme involved in biosynthesis of glycosylphosphatidylinositol anchors. Reduced levels of two GPI anchor markers has been demonstrated in patients with CHIME syndrome. We describe an additional patient with typical clinical features of CHIME syndrome including ichthyosiform dermatosis, retinal coloboma, hearing loss, intellectual impairment, seizures and compound heterozygous mutations in PIGL. Furthermore, this patient shares two mutations with an already described case, including loss of an essential splice site and a founder mutation shared by all reported CHIME cases. CHIME syndrome is an important but overlooked differential for patients with neurological features, including seizures and intellectual disability, and ichythosis. There are striking similarities in clinical features in all of the patients previously described and molecular genetic testing may be used to confirm a clinical diagnosis.

\section{INTEGRATION OF MULTICENTRE DATA TO FURTHER CHARACTERISE THE PHENOTYPES OF RARE CLINICALLY SIGNIFICANT HAEMOGLOBINOPATHY MUTATIONS}

A. Alam ', M. Petrou' ${ }^{2}$ HY. Law ${ }^{3}$, I. Ng ${ }^{4}$, A. Adrahtas', J. Wells', R. Li'; KM. Weekes', SR. Pasricha', DK. Bowden'

\footnotetext{
${ }^{1}$ Clincal Genetics Laboratory, Monash Medical Centre, Southern Health, Melbourne, Australia

${ }^{2}$ Haemoglobinopathy Genetics Centre, University College London and University College London, Hospitals NHS Foundation Trust, London, UK

${ }^{3}$ DNA Diagnostic and Research Laboratory, Genetics Service, Department of Paediatric Medicine, KK Women's and Children's Hospital, Singapore

${ }^{4}$ National Thalassaemia Registry, KK Women's and Children's Hospital, Singapore
}

The haemoglobinopathies are common inherited disorders. Although the majority are caused by a small number of frequently occurring mutations, many rare mutations collectively contribute considerably to the clinical burden. Population screening to document genotype and allele frequencies, availability of high throughput technologies, advances in the lower income countries and antenatal screening programmes has led to an increase in data accumulation. However, phenotype data on rare mutations often remains inadequate and based on a single report. A standard system for collecting and reporting genotype and phenotype for rare mutations would assist in clinical management of patients and couples at-risk.

We report collective phenotype data for a number of relatively rare mutations identified in long established haemoglobinopathy referral laboratories in three countries. For example, the Codon 22 $(\mathrm{C}>\mathrm{T})$ and codon $108(\mathrm{C}>\mathrm{A}) \alpha 2$ globin gene mutations have only been reported on single patients. We present data on eight heterozygous/compound heterozygous patients for each mutation. The $\alpha 1$ globin gene codon 108/109(-C) mutation has no documented phenotype data. We present data for seven heterozygous patients. The IVS2-478 (C-A) $\beta$-globin mutation has been reported once in the literature whilst data for fourteen patients are presented. We describe the previously unreported phenotype for compound heterozygous patients for the deletion of HS-40 regulatory element $/ \alpha 3.7$ dele- tion, $\alpha 3.7$ deletion $/ \alpha 3.5$ deletion, $\alpha 2 \operatorname{cd} 22(\mathrm{C}>\mathrm{T}) / \alpha 2 \operatorname{cd} 59(\mathrm{G}>\mathrm{A})$, cd59(G $>$ A) $/ \mathrm{Hb}$ Constant Spring and Hb Phnom Penh/_SEA .

The collective data presented here updates phenotype data significantly and demonstrates the value of combining the experience of multiple laboratories.

\section{A. CASE STUDY: CHARACTERISATION AND IMPLICATIONS OF RING CHROMOSOME 21 IN A FEMALE CARRIER}

A. Biswas', J. M. M. Chan², S. Y. N. Chan², C. L. M. Chua ${ }^{2}$, L. Gole' ${ }^{2}$, Y. Y. Shen ${ }^{2}$, V. Y. J. Toh' ${ }^{2}$ Y.C. Wong'

${ }^{1}$ Department of Obstetrics and Gynaecology, National University Hospital, Singapore, ${ }^{2}$ Department of Laboratory Medicine, Cytogenetics Laboratory, National University Hospital, Singapore

A 30 year old female presented for prenatal diagnosis at 17 weeks of gestation. She had a history of three previous missed abortions between 6-8 weeks of gestation. The results of the amniotic fluid in-situ cultures showed a male fetus with a mosaic karyotype of 46,XY,r(21)(p11.2q22.3)[12]/45,XY,-21[3]. Peripheral blood analysis of the mother proved she was the carrier with a similar karyotype of 46,XX,r(21)(p11.2q22.3)[267]/45,XX,-21[13]. FISH was used to characterize the ring chromosome and all 3 terminal probes used proved to be present. Ultrasound showed all fetal parameters to be within normal range. On 21q22.3, beyond BAC probe RP1171A7, our most distal probe, there seem to be 2 significant genes, PRMT2 and S100B. We deduce that the breakpoint lies beyond this as the mother presents as normal. On $21 \mathrm{p} 11.3$, there are no discernibly significant genes that have been characterised. This could explain why the mother, despite having no normal XX cell line, is still phenotypically normal.

The reason for the previous miscarriages can be attributed more to the structural interference of the ring chromosome rather than loss of genetic material on 21pter and 21qter. This is because there have been several case reports of liveborn with monosomy 21 and $\mathrm{r}(21)$. The patient was counselled with the probability that this current pregnancy would likely result in a healthy offspring as the fetal karyotype seemed similar to the mother's.

In conclusion, characterisation of ring chromosomes is a big help for future counseling of other patients with similar chromosomal abnormalities.

\section{B. IN VITRO STUDY OF THE ANTI OXIDANT EFFECT OF ASTAXANTHIN AND VITAMIN E ON CULTURED LYMPHOCYTS FROM FANCONI ANEMIA PATIENTS}

Maha M. Eid', Sami A. Temtamy², Engy S. Soliman', Marwa I. Shehab', Sami H. Abd Alaziz ${ }^{3}$, Dina H. Baraka ${ }^{3}$

${ }^{1}$ Human Cytogenetics Department-National research Center-Cairo- Egypt, ${ }^{2}$ Clinical Genetic Department- National Research Center-Cairo- Egypt, ${ }^{3}$ Faculty of science-Banha University Banha- Egypt

Fanconi anemia (FA) is an autosomal recessive genetic disorder in which patients suffer from congenital abnormalities and develop bone marrow failure and aplastic anemia. So far, 15 complementation groups have been identified. Hypersensitivity of FA cells to diepoxybutane (DEB) provides a unique marker for diagnosis.

Besides the hypersensitivity to cross-linking agents, FA cells are also hypersensitive to oxygen, pointing to an important function of FA genes in defense against reactive oxygen species (ROS). In this context, protective effect of some anti oxidant such as super oxide dismutase (SOD), catalase, ascorbic acid and vit $\mathrm{E}$ on chromosomal breakage was studied in FA lymphocytes and fibroblasts however not all of them were proven to be effective.

In this study we have focused on the role of antioxidant in improving the sensitivity of FA chromosomes to the oxidative damage. We have chosen a plant extract Astaxanthin which belongs to the 
carotinoid family but ten times more potent in its antioxidant effect and more safe, to evaluate its effect for patients with FA anemia. Also, we compared its effect with the protective effect of vitamin $\mathrm{E}$.

The results revealed that, vitamin $\mathrm{E}$ and astaxanthin have reduced the caffeine induced chromosomal breakage to significant values upon using on the cultured lymphocytes from patients with FA. So, using these anti oxidant could be valuable for FA patients because oxidation was proved to increase telomeric shortening and apoptosis in hematopoietic cells which lead to the development of pancytopenia. Till now addition of anti oxidant to the therapeutic regimen for FA was neglected inspit of its importance.

\section{POOLING/BOOTSTRAP-BASED GWAS (PBGWAS) IDENTIFIES NEW LOCI MODIFYING THE AGE OF ONSET IN PSEN1 E280A ALZHEIMER'S DISEASE}

M. Arcos-Burgos ${ }^{1,3,4}$, J. Velez' ${ }^{1}$ SC Chandrasekharappa ${ }^{2}$, E. Henao ${ }^{3}$,

A. Martinez' ${ }^{1}$, . Lopera ${ }^{3}$

${ }^{1}$ Medical Genetics Branch, National Human Genome Research Institute, NIH, Bethesda, USA

${ }^{2}$ Genome Technology Branch, National Human Genome Research Institute, NIH, Bethesda, USA,

${ }^{3}$ Grupo de Neurociencias de Antioquia, Universidad de Antioquia, Medellin, Colombia, ${ }^{4}$ John Curtin School of Medical Research, Australian National University, Canberra, Australia

The literature on GWAS data suggests that very large sample sizes (e.g. 50,000 cases and 50,000 controls) may be required to detect significant associations of genomic regions for complex disorders such as Alzheimer Disease (AD). Because of the challenges of obtaining such large cohorts, we describe here a novel sequential strategy that combines pooling of DNA and bootstrapping ( $p b$ GWAS) in order to significantly increase the statistical power and exponentially reduce expenses. We applied this method to a very homogeneous sample of patients belonging to a unique and clinically well-characterized multigenerational pedigree with one of the most severe forms of early onset AD, carrying the PSEN1 p.Glu208Ala mutation (often referred to as E280A mutation), which is originated as consequence of a founder effect. In this cohort, we identified novel loci genome-wide significantly associated as modifiers of the age of onset of $\mathrm{AD}\left(C D 44, \mathrm{rs} 187116, P=1.29 \times 10^{-12} ; N P H P 1, \mathrm{rs} 10173717\right.$, $P=1.74 \times 10^{-12} ;$ CADPS2, rs $3757536, P=1.54 \times 10^{-10} ;$ GREM2, rs $12129547, P=1.69 \times 10^{-13}$, among others) as well as other loci known to be associated with AD. Regions identified by $p b$ GWAS were confirmed by subsequent individual genotyping. The $p b$ GWAS methodology and the genes it targeted could provide important insights in determining the genetic causes of AD and other complex conditions.

\section{EFFECTS OF LPHN3 ON ADHD, SUBSTANCE USE} DISORDER AND DISRUPTIVE BEHAVIORS

\footnotetext{
M. Arcos-Burgos ${ }^{1,5}$, M. Ribases ${ }^{2}$, A. Martinez' , F. X. Castellanos ${ }^{3}$, J. De Leon ${ }^{4}$, M. Muneke

${ }^{I}$ National Human Genome Research Institute, National Institutes of Health, Bethesda, USA,

${ }^{2}$ Departament de Genetica, Facultat de Biologia, Universitat de Barcelona, Barcelona Spain,

${ }^{3}$ Child Study Center, NYU, USA

${ }^{4}$ University of Kentucky, College of Medicine, Department of Psychiatry, Lexington, USA,

${ }^{5}$ John Curtin School of Medical Research, Australian National University, Canberra, Australia
}

Latrophilins comprise a new class of orphan G protein-coupled receptors that regulate neurotransmitter exocytosis. Latrophilins are specific receptors for alpha-latrotoxin, a neurotoxin present in black widow spider venom. We recently found latrophilin 3 (LPHN3), the most brain-specific latrophilin in mammals, to be associated with susceptibility for attention deficit/hyperactivity disorder (ADHD), the most prevalent behavioral disorder in children and adolescents. Since ADHD is usually comorbid with other behavioral conditions, we further interrogated LPHN3 markers for comorbid nicotine and alcohol abuse, conduct disorder and oppositional defiant disorder in three independent samples, from Colombia, Kentucky, USA, and Spain. In each sample, markers were associated with substance use disorder (SUD). These results, together with previous findings implicating LPHN3 in the etiology of ADHD, strongly associate LPHN3 to a variant of ADHD highly comorbid with disruptive behavior disorders and drug abuse. Further research and development of psychiatric drugs targeting this receptor family might provide prevention as well as improvement of the prognosis of both ADHD and similar comorbid conditions associated to SUD.

38. GWAS REVEALS NEW RECESSIVE LOCI ASSOCIATED WITH NON-SYNDROMIC FACIAL CLEFTING

\author{
M. Arcos-Burgos ',5,6, M. Camargo' , D. Rivera' ', L. Moreno ${ }^{2,3}$, A. Lidral' \\ SC Chandrasekharappa ${ }^{4}$, B.D. Solomon ${ }^{5}$ \\ ${ }^{1}$ Population Genetics and Mutacarcinogenesis Group, University of Antioquia, \\ Medellin, Colombia, \\ ${ }^{2}$ Department of Orthodontics, College of Dentistry, University of Iowa, Iowa City, USA, \\ ${ }^{3}$ Dows Institute for Dental Research, College of Dentistry, University of Iowa, Iowa \\ City, USA, \\ ${ }^{4}$ Genome Technology Branch, National Human Genome Research Institute, NIH, \\ Bethesda, USA, \\ ${ }^{5}$ National Human Genome Research Institute, National Institutes of Health, Bethesda, \\ USA, \\ ${ }^{6}$ John Curtin School of Medical Research, The Australian National University, \\ Canberra, Australia
}

We have applied a GWAS to 40 consanguineous families segregating cases of non-syndromic cleft lip with or without cleft palate (NS $\mathrm{CL} / \mathrm{P}$ ) (a total of 160 affected and unaffected individuals) in order to trace potential recessive loci that confer susceptibility to this common facial malformation. Pedigree-based association test (PBAT) analyses reported nominal evidence of association and linkage over SNP markers located at $11 \mathrm{q} 25$ (rs4937877, $\left.P=2.7 \times 10^{-6}\right), 19 \mathrm{p} 12$ (rs4324267, $\left.P=1.6 \times 10^{-5}\right), 5 \mathrm{q} 14.1\left(\mathrm{rs} 4588572, P=3.36 \times 10^{-5}\right)$, and $15 \mathrm{q} 21.1$ (rs4774497, $\left.P=1.08 \times 10^{-4}\right)$. Using the Versatile Gene-Based Association Study (VEGAS) to complement the PBAT results, we found that clusters of markers located at chromosomes $19 \mathrm{p} 12,11 \mathrm{q} 25$, and 8p23.2 overcome the threshold for GWAS significance $\left(P<1 \times 10^{-7}\right)$. From this study, new recessive loci implicated in NS CL/P include: B3GAT1, GLB1L2, ZNF431, ZNF714, and $C S M D 1$, even though the functional association with the genesis of NS CL/P remains to be elucidated. These results emphasize the importance of using homogeneous populations, phenotypes, and family structures for GWAS combined with gene-based association analyses, and should encourage other researchers to evaluate these genes on independent patient samples affected by NS CL/P.

\section{HDAC6 INHIBITORS: A NOVEL THERAPY FOR RETT} SYNDROME

W.A. Gold', A. Saxena ${ }^{2,3}$, D. Ravine ${ }^{2}, \underline{\text { J. Christodoulou }}{ }^{\text {I, }}$

${ }^{1}$ Genetic Metabolic Research Unit, The Children's Hospital at Westmead, Sydney, Australia

${ }^{2}$ Western Australian Institute for Medical Research, University of Western Australia, Perth, Australia

${ }^{3}$ Omics Science Center, RIKEN Yokohama Institute, Japan

${ }^{4}$ Disciplines of Paediatrics and Child Health and Genetic Medicine, Sydney Medical School, University of Sydney, Australia

Rett syndrome (RTT) is a neurodevelopmental disorder primarily affecting females, and is considered the most common cause of severe mental retardation in girls after Down syndrome. Clinical hallmarks of RTT include developmental and respiratory arrest and seizures. Mutations in the methyl-CpG binding protein 2 (MECP2) gene, a transcriptional regulator, essential for normal brain development, 
are the main cause of RTT. The recent reversibility of the RTT phenotype in mouse models is driving the idea that therapeutic amelioration of the neurological phenotype in RTT patients is possible. Current therapeutic trials in patients and mouse models are aimed at the manipulation of known downstream targets of MeCP2.

Histone deacetylase (HDAC) inhibitors, and in particular HDAC6 inhibitors are attracting emerging interest as therapeutic agents in neurodevelopmental disorders. HDAC6 primarily deacetylates tubulin and is localized predominantly in the cytoplasm where it associates with microtubules. HDAC6 inhibitors impede deacetylation of microtubules by HDAC6, and maintain microtubules in an acetylated state thus increasing their stability.

Preliminary data reveals cells from both RTT patients and mouse models show hypo-acetylated tubulin as well as impaired microtubule dynamics. The selective HDAC6 inhibitor, Tubastatin A is able to increase $M E C P 2$ expression (2-fold) as well as acetylated tubulin protein levels (9-fold).

Tubastatin A may be able to compensate for the deficiencies in tubulin acetylation and $\mathrm{MeCP} 2$ expression. We are currently examining the functional association between MeCP2, HDAC6 and Tubastatin A and exploring whether Tubastatin A can ameliorate the motor and behavioural phenotype in a truncated Mecp 2 mutant mouse model.

40. DECISION MAKING FOLLOWING GENETIC COUNSELLING FOR SECOND TRIMESTER ULTRASOUND MARKER FOR ANEUPLOIDY - A REVIEW OF OUTCOMES AT THE ROYAL WOMEN'S HOSPITAL GENETIC COUNSELLING SERVICE, MELBOURNE, AUSTRALIA.

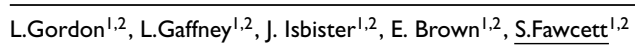

${ }^{1}$ Victorian Clinical Genetics Services, Parkville, Victoria,

${ }^{2}$ Genetic Counselling Service, The Royal Women's Hospital, Parkville, Victoria

A second trimester ultrasound marker for aneuploidy is defined as an ultrasound finding in the fetus that when present increases the risk of a chromosomal problem like Down syndrome. On their own they do not constitute a fetal abnormality. The markers of concern includes thickened nuchal fold (NF), renal pylectasis, echogenic fetal bowel (EB), Echogenic intracardiac focus (EIF), shortened femur, shortened humerus, choroid plexus cysts (CPC) and hypoplastic nasal bone (NB).

The identification of a marker at a routine ultrasound is an unexpected finding for many women who previously considered their risk for Down syndrome as low having already had screening through a population screening program. We are interested in examining this particular group of women and their decisions with regard to follow up given the often complex information and high levels of anxiety they may be experiencing. Other studies have indicated that many but not all women proceeded with amniocentesis, with the single most important factor being the type of marker identified and its association with aneuploidy.

At the Royal Women's Hospital if a marker is confirmed on an in-house ultrasound examination the patient is offered referral to the genetic counselling service.

This review will look at cases referred to our service for counselling following the detection of an ultrasound marker over a 6 month period. We will present our findings including a description of our counselling protocol, decisions made regarding follow up by our cohort, and any implications for genetic counselling in this scenario.

\section{AN EXPLORATION OF THE CLINICAL EXPERIENCES AND ATTITUDES OF AUSTRALIAN HEALTH PROFESSIONALS IN REGARD TO DIRECT-TO-CONSUMER (DTC) GENETIC TESTING}

A. Groves', K. Barlow-Stewart ${ }^{1,2}$, B. Meiser

${ }^{1}$ Sydney Medical School, University of Sydney, Sydney, NSW, Australia

${ }^{2}$ Centre for Genetics Education, Royal North Shore Hospital, St. Leonards, NSW, Australia

${ }^{3}$ Psychosocial Research Group, Prince of Wales Hospital, Sydney, NSW, Australia

Direct-to-consumer (DTC) genetic testing offered via the internet without a doctor's referral is growing worldwide and it is causing concern among genetics professionals, public health bodies, consumer advocates and governments for a variety of medical, ethical and legal reasons. To date several quantitative studies have explored the views and attitudes of many of these groups but this qualitative research explores the clinical experiences, views and attitudes of health professionals with patients who have undertaken DTC genetic testing. The impact they believe DTC testing is having on healthcare practice and services is also explored. The aim of this study is to develop an in-depth understanding of how genetic and non-genetic health professionals are managing DTC genetic testing results brought to them by new or current patients and the resulting impact on services that they provide.

Data collection will take place through the use of semi-structured interviews with up to ten genetic and non-genetic health professionals who have been involved with patients who have undertaken DTC genetic testing. Recruitment will be from professionals who have previously indicated their interest in discussing their experience. Snowballing will be used to recruit other health professionals. Interviews will continue until data saturation is reached. The data will be analysed using thematic analysis. It is expected that the outcomes of this study will further inform the impact that DTC testing is having in Australia and guide the resource and support needs of consumers who access DTC genetic testing and their health professionals.

\section{CHALLENGES FACED BY HEALTH CARE INTERPRETERS PRACTICING IN GENETIC COUNSELLING SERVICES}

\section{E. Harrison', K. Barlow-Stewart' ${ }^{1,2}$, M. Saleh ${ }^{1,2}$}

${ }^{1}$ Faculty of Medicine, University of Sydney, NSW, Australia,

${ }^{2}$ The Centre for Genetics Education, Royal North Shore Hospital, St Leonards, NSW, Australia

This study aims to identify the challenges faced by interpreters practicing in genetic counselling services.

Genetic counselling is defined as a process of communication and supportive counselling between a patient and genetic clinician, with regards to risk, health, and the impact of genetic conditions. This process of communication and understanding can be compromised by language and/or cultural barriers that may occur with individuals with cultural and linguistic diversity (CALD). Furthermore, the utilisation of Health Care Interpreters in clinical genetics settings, may raise additional issues that challenge the genetic counselling process.

Group 1 will consist of approximately 20-30 Genetic Clinicians in NSW. These individuals will have previously worked in a genetic counselling setting, which required the use of an interpreter for translation.

Group 2 will consist of approximately ten (10) Health Care Interpreters. These individuals will have previously worked in a genetic counselling setting in NSW.

Following analysis of the data that results from this study, it is hoped that the researchers will develop strategies and resources that will aim to help both genetic clinicians and interpreters overcome their challenges when communicating with CALD individuals and families in a genetics setting.

\section{PREDICTORS OF GENETIC INFORMATION DISCLOSURE} BY CF OBLIGATE CARRIERS TO AT-RISK RELATIVES

K. Barlow-Stewart', M. Leffler' ${ }^{2}$, M. Saleh', C. Shalhoub ${ }^{3}$

${ }^{1}$ Centre for Genetics Education, The Royal North Shore Hospital, NSW, Australia, 
${ }^{2}$ Medical School, The University of Sydney, NSW, Australia,

${ }^{3}$ Department of Medical Genetics, The Sydney Children's Hospital, Randwick, NSW, Australia

Cystic fibrosis (CF) is a life-limiting, life-altering condition characterised by multi-organ dysfunction including increased respiratory infections due to reduced airway clearance of mucosal secretions, pancreatic insufficiency, male infertility, and faulty electrolyte secretions of the sweat gland. $\mathrm{CF}$ is a recessive genetic condition caused by mutations of the CFTR gene. The carrier frequency of CF is as high as one in 25 in Caucasian populations. Due to this high carrier frequency, it was of interest to explore predictors of CF genetic information dissemination that biological parents of affected $\mathrm{CF}$ children display to at-risk family members and the reported reasons for their pattern of disclosure/non-disclosure. This project is in the recruitment stage and will utilise a mixed-method approach whereby a questionnaire will be sent to obligate carriers of CF that frequent The Sydney Children's Hospital, Randwick CF clinic. Additional optional interviews will be conducted with a sub-population of participants to further explore the reported reasons for the pattern of disclosure. Future studies will seek to compare and contrast disclosure behaviours of obligate carriers and families with infants identified as CF carriers through newborn screening programs. Ultimately, this research aims to explore ways to provide effective genetic counselling tools to aid families in disclosure of genetic information to at-risk family members.

\section{LIFE INSURANCE AND GENETIC TESTING - POLICY} CHANGES AND IMPLICATIONS

\section{Barlow-Stewart, K}

Centre For Genetics Education, ST LEONARDS, NSW, Australia

The Life Insurance industry in Australia's genetic testing policy became a standard (\#11) in 2005 making it mandatory practice. The standard states that genetic testing would not be requested for applicants for new life insurance products or when applying for increases to existing policies. Such products include income protection, trauma and permanent and total disability insurance. If however an applicant knew their genetic test result, or their blood relative's test result, they must disclose it in the application as the contract is one of good faith: the insurer needs to know what the applicant knows. In this context, family health history also needed to be disclosed. An important interpretation of the policy was that if the genetic test was undertaken as part of a research project where the result was not to be returned, the applicant did not have to disclose ever having had the test. In 2011, the Financial Services Council, representing Life Insurance companies in Australia introduced several changes to how applications were underwritten. Amendments to standard \#16 (Family Medical History) were instituted whereby disclosure of family history was limited to only first degree relatives in recognition of the difficulties some applicants were experiencing. However, applicants now must disclose whether they have had a genetic test, even if it was in a research project where they would not receive a result. In the latter case, the insurers undertake not to take into account when underwriting a policy that a genetic test has been undertaken. Implications of these changes to policy will be discussed.

This also Recommendations in the Australian Law Reform Commission's 2003 report Essentially Yours: The Protection of Human Genetic Information in Australia that were addressed to the Life Insurance Industry have guided the work of the NHMRC in this area. The life insurance industry represented by the Financial Services Council (FSC) has been working with the NHMRC on several issues generated by genetic testing for consumers applying for new life insurance products or for changing an existing policy.
45. FAMILY TESTING FOR A MICRODELETION FOUND ON MICROARRAY CGH IN A PRENATAL SETTING

K. Murphy, R. Robertson, G. Kesby, J. Hayward

Sydney Ultrasound for Women, Chatswood, NSW, Australia

A 36 year old woman presented for a CVS in her second pregnancy due to advanced maternal age (AMA). She was offered chromosome testing via qfPCR for chromosomes 21, 18, 13 and $\mathrm{X}$ and $\mathrm{Y}$ and SUFWprenatalArray (Sydney Ultrasound for Women targeted microarray CGH for approximately 250 genetic conditions relevant in the prenatal setting). The microarray revealed an hemizygous loss of approximately $200 \mathrm{~kb}$ at $16 \mathrm{p} 13.3$ of potential clinical significance. The micodeletion contained the FOX1 gene. Literature pertaining to this microdeletion is limited however deletions have been associated with neurodegenerative disorders, epilepsy and mental retardation. Parental microarrays were requested which revealed paternal inheritance of the deletion. This provided some reassurance to the couple that the deletion was likely to be benign. However, due to reduced penetrance and variable expressivity, no guarantee of clinical effect could be given to the couple. Due to high anxiety, the couple sought more information and elected microarray testing in their daughter of 23 months of age as well as the paternal grandparents. Family studies showed possession of the microdeletion in the couple's daughter and the paternal grandfather. The presence of the microdeletion in three unaffected individuals gave the couple the reassurance they required to continue the pregnancy. This case highlights the challenge of using microarray CGH in the prenatal setting where certainty of diagnosis is sought but cannot always be provided and anxiety is high. Family testing in this case was informative and allowed the couple to move forward with confidence.

\section{FIRST IMPRESSIONS COUNT! COMPARISON OF CLIENT SATISFACTION AND DISTRESS BETWEEN THREE DIFFERENT INTAKE PROCESSES TO A FAMILY CANCER CLINIC}

T. Silberbauer' ${ }^{\text {, R. Williams }}{ }^{2}$, C. E. Wakefield ${ }^{3}$, R. Nicholls', K. Barlow-Stewart ${ }^{1,4}$

${ }^{I}$ Sydney Medical School, University of Sydney, NSW,

${ }^{2}$ Hereditary Cancer Clinic, Prince of Wales Hospital, Randwick, NSW,

${ }^{3}$ School of Women's and Children's Health, University of NSW and Centre for Children's Cancer and Blood Disorders, Sydney Children's Hospital.

${ }^{4}$ Centre for Genetics Education, Royal North Shore Hospital, St Leonards, NSW

Effective genetic counselling requires establishing a good working relationship between clients and genetic counsellors. Such a relationship usually starts during intake to the clinic. There is little published research looking at intake processes in genetic counselling in Australia, although some data are available examining the use of family history questionnaires in the UK and Canada. There is a clear gap in research to address the attributes of the three commonly-used intake procedures from clients', genetic counsellors' and clinicians' viewpoints: face-to-face intake (interview), telephone intake, and independent completion of a family history questionnaire. In this study we compare client satisfaction and distress for cohorts of clients going through one of these intake processes. Clients referred to the Hereditary Cancer Clinic at the Prince of Wales hospital, who consent to be part of the study, were randomly allocated to one of the three intake groups. Following intake they were asked to complete three questionnaires - one immediately prior to their first clinic appointment, one immediately after their first clinic appointment, and one three months after their first clinic appointment. The questionnaires consisted of a five-point client distress measure (distress thermometers) and a six point client satisfaction measure (satisfaction with genetic counselling). Demographic/clinical data were also collected. Preliminary results from the first two questionnaires will 
be presented. This study is part of a larger study examining clinician experience and comparing administrative factors between different intake processes.

\section{FIRST IMPRESSIONS COUNT! COMPARISON OF THREE 'FAMILY HISTORY INTAKE PROCESSES'; INFLUENCE OF INTAKE PROCESS ON CLINICIAN AND GENETIC COUNSELLOR EXPERIENCE AND SATISFACTION}

\author{
R. Nicholls ', L. Silberbauer' , R. Williams ${ }^{2}$, C. Wakefield ${ }^{3,4}$, K.Barlow-Stewart ${ }^{1,5}$ \\ ${ }^{1}$ Sydney Medical School, University of Sydney, Sydney, NSW, Australia \\ ${ }^{2}$ Hereditary Cancer Clinic, Prince of Wales Hospital, Randwick, NSW, Australia \\ ${ }^{3}$ School of Women's and Children's Health, University of New South Wales, Randwick, \\ NSW, Australia \\ ${ }^{4}$ Centre for Children's Cancer and Blood Disorders, Sydney Children's Hospital \\ Randwick, NSW, Australia \\ ${ }^{5}$ Centre for Genetics Education, Royal North Shore Hospital, St Leonards, NSW, \\ Australia
}

There is limited peer reviewed research investigating the techniques used by genetic counsellors in Australia for initial contact with clients. International research has explored the effectiveness of family history questionnaires, however client, genetic counsellor and clinician perspectives of commonly used intake processes in Australia has not previously been addressed.

In this study, we compared intake processes of face-to-face interviews, telephone intake and family history questionnaire. Clinicians and genetic counsellors from the Hereditary Cancer Clinic, Prince of Wales Hospital were asked to complete a brief (3 question) questionnaire after each client's first clinic visit, assessing the clinician's opinion of the quality of family history taken prior to clinic and the clinician's opinion of the client's preparedness for clinic.

Towards the end of the study the researchers will conduct telephone or face-to-face interviews with clinicians and genetic counsellors associated with the clinic. The interviews will explore the clinicians' experiences with the three intake procedures, the way clients from each intake group presented for clinic, any differences in interaction between clinicians and clients from each intake group, and suggestions for improvement to intake processes. Additional genetic counsellors from Australia and New Zealand will be invited to participate in a telephone or face-to-face interview to discuss their own experiences with intake processes. We will present preliminary results from the brief questionnaire and additional interviews. This study forms part of a larger study examining both client and clinician satisfaction and experience, as well as comparing administrative factors between different intake processes.

\section{ASSESSMENT OF PATIENT AND RELATIVES' UNDERSTANDING OF 'NO MUTATION FOUND' AND 'UNCLASSIFIED VARIANT' BRCA1/BRCA2 GENE TEST RESULTS AND EFFECT ON HEALTH BEHAVIOURS}

J. Berkman', R. Simpson², R. Susman', M. Peterson ${ }^{2}$

${ }^{1}$ Genetic Health Queensland, Royal Brisbane and Women's Hospital, Herston Australia,

${ }^{2}$ Department of Biomolecular and Physical Sciences, Griffith University, Brisbane, Australia

Diagnostic breast cancer gene testing aims to determine the cause of familial breast cancer predisposition. When a BRCA1 or BRCA2 gene mutation is found in an individual there are guidelines for screening and options for prophylactic surgery to mitigate this risk. In addition, these patients have a genetic counselling appointment to discuss results and are provided with a 'family letter' to disseminate information to relatives. Those who receive a 'no mutation found' (negative) or 'unclassified variant' (UCV) result are generally notified by telephone and letter by our service. This study aims to determine whether patients and their relatives understand and inter- pret appropriately their personal and family risk of cancer following receipt of negative and UCV test results. We hypothesise that: (1) some patients receiving a negative test result will assume, despite appropriate counselling, that the familial cancer risk is reduced, negatively impacting screening behaviour; and (2) some patients receiving a UCV result will not understand it, potentially impacting psychological wellbeing and/or screening behaviour. To test our hypotheses, approximately 200 questionnaires have been sent to individuals who have received negative or UCV results with additional questionnaires enclosed for interested relatives. Recall of risk category, cancer risk perception, communication with relatives, cancer risks for first-degree relatives and the effect of test results on screening and other positive health behaviours are investigated. Results will be used to improve protocols and communication strategies for providing these test results through Genetic Health Queensland. Preliminary results of this study are presented here.

\section{THE IMPORTANCE OF CONFIRMING CFTR MUTATION GENOTYPES FOR AFFECTED INDIVIDUALS AND THE SIGNIFICANCE OF THIS INFORMATION FOR EXTENDED FAMILY MEMBERS, CLINICAL CARE AND FUTURE REPRODUCTIVE DECISION MAKING.}

\section{B. Burgess', L. Christie', S. O’Donnell', B. Whitehead², M. Edwards'}

\author{
${ }^{1}$ Hunter Genetics, Waratah, Australia, \\ ${ }^{2}$ John Hunter Children's Hospital-Paediatric Respiratory Department, New Lambton, \\ Australia
}

We report on 8 years experience working in a multidisciplinary setting with the Paediatric Respiratory Team at John Hunter Children's Hospital to confirm the Cystic Fibrosis Transmembrane Conductance (CFTR) mutations in all affected paediatric patients. This information is essential for cascade testing in the family, reproductive decision making for the proband and relatives and has relevance for clinical care and therapeutic trials. The availability of sequencing of the CFTR gene in the clinical setting has impacted on the genetic services available and the role of the genetic counsellor. The genetic testing service at Hunter Genetics is a specialty area coordinated by a genetic counsellor in an autonomous role.

\section{EXPERIENCES OF PARENTS CONSIDERING GENETIC TESTING TO BETTER UNDERSTAND THEIR CHILD(REN)'S RISK OF DEVELOPING FAMILIAL HYPERTROPHIC CARDIOMYOPATHY (HCM) OR LONG OT SYNDROME} (LQTS).

C. Spinks' , N. Kasparian 2,3 , I. Macciocca ${ }^{4}$, M. Wilson ${ }^{5}$, F. Collins ${ }^{5}$,

R. Macintosh ${ }^{6}$, K. Barlow-Stewart ${ }^{1,7}$, E. Kirk ${ }^{6}$

${ }^{1}$ Sydney Medical school, University of Sydney, Sydney, NSW, Australia

${ }^{2}$ Heart Centre for Children, Children's Hospital at Westmead, Westmead, NSW, Australia

${ }^{3}$ Faculty of Medicine, UNSW, Sydney, NSW, Australia

${ }^{4}$ Genetic Health Services Victoria, Royal Children's Hospital, Melbourne, VIC, Australia

${ }^{5}$ Department of Clinical Genetics, Children's Hospital at Westmead, Westmead, NSW, Australia

${ }^{6}$ Department of Medical Genetics, Sydney Children's Hospital, Randwick, NSW, Australia

${ }^{7}$ Centre for Genetic Education, St Leonards, NSW, Australia

Inherited forms of the cardiac conditions LQTS and HCM have elements in common, the most serious concern being the risk of sudden cardiac death. Adolescence has been identified as a high-risk time for symptoms to develop. As cardiac monitoring and potential treatment start at an early age for both conditions, parents are given the option to consent for predictive genetic testing on behalf of minors. There is currently a gap in the literature on the parental perspective on genetic testing for HCM or LQTS in children. 
This study aims to provide a rich and meaningful description of the psychosocial experience of parents who are considering genetic testing in their child(ren) to better understand their child(ren)'s risk of developing LQTS or HCM.

Parents will be recruited at their first genetics appointment to discuss genetic testing for their child(ren). Parents will be invited to take part in a semi-structured interview three months after receiving their child's test result (or equivalent time for those who do not proceed with testing) to explore parents' reflections on the experience as well as their psychosocial care needs. Narrative analysis will be utilised to present parents' stories as coherent and temporally ordered descriptive accounts. The analysis process will be clearly outlined with the aim of producing maximum transparency in results.

New research that leads to a greater understanding of the psychosocial experiences of parents in this situation will help guide future clinical practice and resources, in how best to support families through this process.

\section{IS IT TOO LATE FOR ONE FAMILY TO BE ABLE TO UTILISE PRENATAL TESTING FOR TUBEROUS SCLEROSIS AND HAVE A HEALTHY BABY?}

\author{
M. Sproule', G. McGillivray ${ }^{2}$, L. Sheffield ${ }^{2}$, A. Yeung ${ }^{2}$ \\ ${ }^{1}$ Genetic Health Services Victoria, Albury/Wodonga, Australia \\ ${ }^{2}$ Genetic Health Services Victoria, Melbourne, Australia
}

Tuberous Sclerosis (TS) is an autosomal dominant condition characterized by abnormalities of the skin, brain, kidneys, heart and lungs. It can also cause seizures and intellectual disability. Mutations in TSC1 and TSC2 can be found in approximately $85 \%$ of individuals who meet diagnostic criteria for TS.

TL, a twenty one year old woman was referred to our genetics service with a suspected diagnosis of TS. An ultrasound had shown bilateral renal angiomyolipomas and subsequent MRI of her brain revealed cortical hamartomas. TL's disease was classified as mild in the absence of seizures, skin lesions or cardiac tumours. She also had normal intelligence. At the time TL was seen, she already had two healthy children. Initial DNA testing was inconclusive so prenatal testing was unavailable.

TL presented again with a pregnancy to a new partner. An 18 week ultrasound showed cardiac rhabdomyomas indicating that the baby was affected with TS. TL subsequently underwent a termination of pregnancy. With further family DNA studies a gene change was identified which segregated with disease in the family and deemed to be pathogenic. Prenatal testing was performed in a subsequent pregnancy which revealed a second affected baby, leading to a termination of pregnancy. PGD is currently being explored.

\section{PROVIDING WRITTEN INFORMATION FOR CONSUMERS ON RARE GENETIC CONDITIONS - ATTITUDES TOWARDS AND THE USE OF GENETICS INFORMATION SHEETS}

S. Troth', K. Dunlop', K. Barlow-Stewart ${ }^{1,2}$, M. Saleh ${ }^{1,2}$.

${ }^{1}$ The Centre for Genetics Education NSW Health, Royal North Shore Hospital, NSW, Australia

${ }^{2}$ Sydney Medical School - Northern, University of Sydney, NSW Australia

Genetics Information Sheets (GIS) have been produced and provided by the Centre for Genetics Education NSW Health to health professionals, individuals and families affected by genetic conditions in NSW since 1998. GIS are produced upon request and are updated if more than 12 months old. GIS provide information about rare genetic conditions, their causes, symptoms, inheritance, prevalence, treatments, genetic testing and support groups and are targeted specifically for the Australian healthcare consumer. The demand for GIS remains high with 239 being sent to requesters in 2011. Greater access and changes to how healthcare consumers seek information, the increase in information and support from support groups and general sources of consumer information, as well as the substantial time required in developing evidence based information sheets, highlight the need for a review of the current GIS and the service provided. An evaluation is being undertaken to identify attitudes towards GIS, their use and accuracy and provide a comparison to a similar review in 2003. Two groups, genetics health professionals listed on the Centre's database that have ordered GIS in the last 3 years and consumers, contacted through the Association of Genetic Support of Australasia (AGSA), are being recruited. A short ten question survey about attitudes towards, use and accuracy of the GIS has been developed for each group. The results of the evaluation will be reported and are intended to inform future directions and further development of genetics information on rare conditions for consumers and contribute to the Centre's strategic plan.

\section{EVALUATION OF A GENERAL PRACTITIONER EDUCATION MODULE ON FIRST TRIMESTER SCREENING AND THE ASSOCIATED GENETIC COUNSELLING SKILLS}

J. Malkoun', K. Dunlop ${ }^{2,}$, K. Barlow-Stewart ${ }^{2,3}$

${ }^{1}$ Master of Genetic Counselling Student, University of Sydney, Sydney, NSW, Australia ${ }^{2}$ The Centre for Genetics Education, Sydney, NSW, Australia

${ }^{3}$ Sydney Medical School, University of Sydney, Sydney, NSW, Australia

Informing pregnant women of all ages about first trimester screening and providing appropriate risk information to enable them to make an informed choice is a NSW Health Government policy requirement. This responsibility usually falls to General Practitioners (GPs) and presents particular challenges in facilitating discussion around pros and cons, risk, possible implications of an increased risk result and decision making. To support GPs and at the request of GP providers of professional development, an education module, First Trimester Screening- it's not a routine test, was developed in 2011 by the Centre for Genetics Education NSW Health. The module included a powerpoint presentation, followed by video case studies of GP consultations, piloted with GPs(60) and genetic counsellors. Found to be excellent and highly relevant it has since been further developed based on feedback, including the addition of a fourth video case study addressing the issues when an increased risk result is received. As part of the final stage of development, a study to evaluate the impact of this revised module on GP knowledge, behaviour and attitude is being undertaken. The study involves a pre and post self-report questionnaire completed by GPs undertaking the education module as part of Continuing Professional Development (CPD) at two NSW Divisions of General Practice. The questionnaire is based on the validated GPGeneQ survey (2010). Results of this study will be reported and inform the final development of the education module to facilitate its use as a CPD activity for GPs across NSW.

\section{USE OF TECHNOLOGY IN MEDICAL GENETICS EDUCATION: LESSONS LEARNED FROM THE UWS MBBS PROGRAM}

\section{J.M. Lind'}

${ }^{1}$ University of Western Sydney, School of Medicine, NSW, Australia

Medicine is traditionally a conservative discipline, rigorously sceptical with scientific evidence, but fast to adopt technological advances. The new School of Medicine at the University of Western Sydney offers a five year undergraduate degree which enrolled its first cohort in 2007. The aim of medical genetics education at UWS is to place an emphasis on understanding the mechanisms that lead to disease and to tell the story behind the subject matter using a range of delivery strategies. The UWS MBBS program combines traditional face to face teaching, with online mini-lectures, interactive 
quizzes as well as animations and videos. This creates an interactive student centred learning environment where the focus is on conceptual knowledge created from research, rather than memorised facts. The students are taught to decipher the cause of disease using upto-date scientific literature and technology, translating experimental evidence into clinical practice. The students have rated the teaching of genetics as the best part of their course and the Senior Lecturer in Molecular Biology and Genetics has been recognised with a number of teaching awards. Student feedback has also been extremely positive - "Summaries were amazing, information given for understanding was great. Used pictures, videos, other materials really well. ... didn't expect previous knowledge but explained it from the very beginning." The Genetics teaching within the UWS MBBS program is at the forefront of learning and teaching in a young medical school and sets an example of how the latest technology can be adopted into medical genetics education.

\section{PUBLIC HEALTH GENOMICS: A NEW CORE SUBJECT FOR THE UNIVERSITY OF MELBOURNE, MASTER OF GENETIC COUNSELLING}

\section{J.L Halliday', T. Charles', A. Herlihy'}

${ }^{1}$ Murdoch Childrens Research Institute, Parkville, Victoria, Australia

Public Health Genomics is a discipline that encompasses scientific advances in genomics and their translation into policy and practice. While many genetic counsellors will enter clinical practice and work with clients, many are choosing to enter fields such as academia, research, public health and health policy and the need for curriculum in Public Health Genomics was recognised. Therefore, in 2011, the University of Melbourne Master of Genetic Counselling course introduced this as a core subject. The aim is to provide education about the most current genomic technologies and how these may impact not only individual health, but also the general public and health service delivery. The subject is also designed to contribute to the skills and knowledge required to be able to consider the public policy implications of the translation of genomic research and technology to whole populations.

The week-long intensive is delivered by local, national and international experts. Topics include population genetic screening, genetics of complex diseases, whole genome sequencing, ethical and legal issues, biobanks and databases, pharmacogenetics, epigenetics, health economics, health policy and genetic literacy and the media. This presentation will provide more details on the subject content.

In its first year, students indicated the subject was interesting, engaging and prompted them to think beyond the clinical setting. It is anticipated that it will become available as an elective for the Master of Public Health program as well as for practicing public health professionals who make policy decisions related to genomic technologies.

\section{SO, WHAT EXACTLY IS THAT YOU DO? PROVIDING GENETIC EDUCATION TO MIDWIVES AND NURSES}

\author{
P.j. McGrath', M. Mitchell ${ }^{2}$ \\ ${ }^{1}$ Genetic Health Queensland, Royal Brisbane and Women's Hospital, Herston, \\ Australia \\ ${ }^{2}$ Maternal and Fetal Medicine, Royal Brisbane and Women's Hospital, Herston, \\ Australia
}

The role of the genetic counsellor in a busy tertiary centre is one that is often shrouded in mystery, or so it would seem. Too often, midwives and their operating theatre colleagues are uncertain as to what role, if any the genetic counsellor plays in the provision of care for the pregnant woman. Counselling is viewed as being required only for the obviously distressed or those who have concurrent social issues. This misconception is perpetuated by the lack of knowledge and appreciation of what the genetic counsellor can bring to the situation and ignores the tortuous journey the woman finds herself on.

Women who present with an abnormal prenatal result require skillful and compassionate care from a wide variety of professionals. However, often the genetic counsellor is overlooked due to a broad ignorance of the role.

One way to leap this chasm of ignorance is to provide in-service that is truly organic in its nature. What knowledge do midwives and nurses need? This dissemination of information is delivered by way of quarterly in-service. The Senior Prenatal Genetic Counsellor and Pregnancy Case Manager from the Royal Brisbane and Women's Hospital provide a back-to-basic session where the myths surrounding genetic counselling and its role in termination of pregnancy are examined.

This presentation will outline the session's aim, contents and evaluation data. It will also discuss the educational philosophy behind the sessions and an overview of the impact it has had on referrals to the service. 